\title{
Adverse Effects of fine particulate matter on human kidney functioning: a systematic review
}

\author{
Leen Rasking ${ }^{1}$, Kenneth Vanbrabant ${ }^{1}$, Hannelore Bové ${ }^{1}$, Michelle Plusquin ${ }^{1}$, Katrien De Vusser ${ }^{2,3}$, \\ Harry A. Roels ${ }^{1,4}$ and Tim S. Nawrot ${ }^{1,5^{*}}$ (i)
}

\begin{abstract}
Background: Ambient fine particulate matter $\left(\mathrm{PM}<2.5 \mu \mathrm{m}, \mathrm{PM}_{2.5}\right)$ is gaining increasing attention as an environmental risk factor for health. The kidneys are considered a particularly vulnerable target to the toxic effects that $\mathrm{PM}_{2.5}$ exerts. Alteration of kidney function may lead to a disrupted homeostasis, affecting disparate tissues in the body. This review intends to summarize all relevant knowledge published between January 2000 and December 2021 on the effects of ambient $\mathrm{PM}_{2.5}$ and the adverse effects on kidney function in adults ( $\geq 18$ years).

Results and Discussion: Studies published in peer-reviewed journals, written in English, regarding the effects of $\mathrm{PM}_{2.5}$ on kidney function and the development and/or exacerbation of kidney disease(s) were included. Of the 587 nonduplicate studies evaluated, 40 were included, comprising of studies on healthy or diagnosed with pre-existing disease (sub)populations. Most of the studies were cohort studies $(n=27)$, followed by 10 cross-sectional, 1 ecological and 2 time-series studies. One longitudinal study was considered intermediate risk of bias, the other included studies were considered low risk of bias. A large portion of the studies $(n=36)$ showed that $\mathrm{PM}_{2.5}$ exposure worsened kidney outcome(s) investigated; however, some studies show contradictory results. Measurement of the estimated glomerular filtration rate, for instance, was found to be positively associated $(n=8)$ as well as negatively associated ( $n$ =4) with $\mathrm{PM}_{2.5}$
\end{abstract}

Limitations and Conclusion: The main limitations of the included studies include residual confounding (e.g., smoking) and lack of individual exposure levels. The majority of included studies focused on specific subpopulations, which may limit generalizability. Evidence of the detrimental effects that ambient $\mathrm{PM}_{2.5}$ may exert on kidney function is emerging. However, further investigations are required to determine how and to what extent air pollution, specifically $\mathrm{PM}_{2.5}$, exerts adverse effects on the kidney and alters its function.

Registration: The systematic review protocol was submitted and published by the International Prospective Register of Systematic Reviews (PROSPERO; CRD42020175615).

Keywords: Air pollution, Fine particulate matter, $\mathrm{PM}_{2.5}$, Kidney, Kidney disease

\section{Background}

The human kidneys are a vulnerable target for exposure to toxic substances due to their filtration function.

*Correspondence: tim.nawrot@uhasselt.be

${ }^{1}$ Centre for Environmental Sciences, Hasselt University, Agoralaan Gebouw D, B-3590 Diepenbeek, Belgium

Full list of author information is available at the end of the article
About $180 \mathrm{~L}$ of blood are filtered per day, of which water, metabolic waste, and toxic components are removed [1]. Altered kidney function may affect homeostasis and, original author(s) and the source, provide a link to the Creative Commons licence, and indicate if changes were made. The images or other third party material in this article are included in the article's Creative Commons licence, unless indicated otherwise in a credit line to the material. If material is not included in the article's Creative Commons licence and your intended use is not permitted by statutory regulation or exceeds the permitted use, you will need to obtain permission directly from the copyright holder. To view a copy of this licence, visit http://creativecommons.org/licenses/by/4.0/. The Creative Commons Public Domain Dedication waiver (http://creativeco mmons.org/publicdomain/zero/1.0/) applies to the data made available in this article, unless otherwise stated in a credit line to the data. 
subsequently, lead to dysfunctions in other tissues [2,3]. Kidney diseases, such as chronic kidney disease (CKD), hold a large burden on public health worldwide [4]; it is estimated that globally, e.g., CKD prevalence amounts to $13.4 \%$ (11.7 - 15.1\%) and progression of the disease may lead to end-stage renal disease (ESRD), requiring dialysis and/or kidney replacement therapy [5]. Furthermore, significant costs can be attributed to requiring dialysis; in 2018, the annual cost for dialysis per person was estimated at 85,966 USD (76,282 EUR) [6].

A significant toxic substance to which everyone is exposed on a daily basis is particulate matter (PM) from ambient air pollution. PM is classified by the International Agency for Research on Cancer (IARC) as carcinogenic to humans [7]. Rather than coarse PM $\left(\mathrm{PM}_{10}\right)$ as the indicator of airborne particulate pollution, fine particulate matter $\left(\mathrm{PM}_{2.5}\right.$; particles having a diameter $<2.5$ microns) has been gaining more attention and is assumed to be more closely associated with adverse health effects linked to outdoor air pollution exposure [8]. In 2016, the World Health Organization (WHO) estimated that annually 4.2 million deaths could be attributed to ambient $\mathrm{PM}_{2.5}$ [9]. As of now, no threshold for $\mathrm{PM}_{2.5}$ has been identified below which it would not pose a threat to human health. Therefore, in 2021, the WHO lowered the annual mean of $\mathrm{PM}_{2.5}$ from $10 \mu \mathrm{g} / \mathrm{m}^{3}$ to $5 \mu \mathrm{g} / \mathrm{m}^{3}$ [10]. $\mathrm{PM}_{2.5}$ has the potential to translocate into the blood [11] and towards distant organs [12,13] following inhalation. In that regard, Saenen et al. [14] showed the presence of black carbon particles - a significant component of $\mathrm{PM}_{2.5}$ - as a marker of medium-term to chronic exposure to combustion-related air pollution in the urine of healthy individuals. The presence of these toxic particles may cause direct or indirect adverse effects on the kidneys. In that regard, $\mathrm{PM}_{2.5}$ has been shown to mediate atherosclerosis development, which may induce vascular dysfunction and result in microvascular damage and atherosclerotic kidney disease [15]. This suggests that inhaled small particles ( $<30 \mathrm{~nm}$ diameter) can selectively accumulate in the kidney during the filtration and excretion processes and subsequently directly induce vascular inflammation, entailing renal damage. Moreover, persons already diagnosed with a disease affecting the kidney (e.g., diabetes mellitus) or with a compromised immune system (e.g., kidney transplant recipients) could experience a worsening of symptoms following increased $\mathrm{PM}_{2.5}$ exposure [16].

The detrimental effects of air pollutants such as $\mathrm{PM}_{2.5}$ on the kidney have just begun to be acknowledged. Therefore, this systematic review aims to (i) summarize the literature regarding ambient $\mathrm{PM}_{2.5}$ exposure and its adverse effects on kidney functioning in humans, (ii) to elucidate the reported detrimental effects on the kidneys, and (iii) to evaluate the research gaps and further research needs.

\section{Methods}

This systematic review was processed according to the Preferred Reporting Items for Systematic reviews and Meta-Analyses (PRISMA) statement [17]. In accordance with these guidelines, our systematic review protocol was submitted and published by the International Prospective Register of Systematic Reviews (PROSPERO; CRD42020175615).

\section{Data Searches and Sources}

Studies addressing the potential effects of ambient $\mathrm{PM}_{2.5}$ exposure on kidney functioning in adults ( $\geq 18$ years) were retrieved according to a four-stage process. In the first stage, potentially eligible studies were identified through a literature search of two bibliographic databases, PubMed (www.pubmed.ncbi.nlm.nih.gov) and Scopus (www.elsevier.com/solutions/scopus), using the $\mathrm{MeSH}$ terms "kidney" and "kidney disease" along with the keywords: "fine particulate matter", "element" carbon", "black carbon", "ufp", ultrafine partic", particul" matter", " $\mathrm{PM}_{2.5}$ ", and "nephropath", "kidney failure", "kidney insufficienc", "renal insufficienc", and "chronic renal". The reference lists of key reviews and the included papers were screened to recover any additional eligible publications to ensure literature completeness. The literature search covered articles published between January 1st, 2000 and December 20th, 2021.

\section{Data Selection and Risk of Bias Evaluation}

In the second stage, two reviewers (LR and KVB) independently screened the titles and abstracts of all identified papers to exclude studies that did not fulfill one or more of the a priori set inclusion criteria. Any disagreement was resolved through discussion. If no consensus could be reached, a third reviewer (HB) was consulted. Duplicate studies were removed. We included longitudinal, cross-sectional, and cohort studies written in English, which addressed the effects of exposure to $\mathrm{PM}_{2.5}$ on the kidney or kidney disease outcomes. Publications describing animal or in vitro studies, or examining exposure to coarse PM $\left(\mathrm{PM}_{10}\right), \mathrm{PM}_{2.5}-10$, and volatile substances [e.g., carbon monoxide $(\mathrm{CO})$, ozone $\left(\mathrm{O}_{3}\right)$, nitrogen dioxide $\left(\mathrm{NO}_{2}\right)$, or sulfur dioxide $\left.\left(\mathrm{SO}_{2}\right)\right]$ were excluded. Additionally, studies focusing on kidney function or disease outcomes in children or adolescents were excluded as the leading causes of the development of kidney diseases vary significantly among these subpopulations $[18,19]$.

In a third stage, full-text articles were retrieved and underwent a second screening for eligibility following the previously described inclusion criteria. According to the 
Newcastle-Ottowa Quality Assessment Scale (NOS) for cohort studies, risk of bias analysis was performed by two independent researchers (LR, KVB). The NOS scale uses a star system to judge a study and to evaluate the risk of bias [20]. The most important adjustable factor for comparability was considered age. The cut-off for the highest risk of bias was set at less than half of the points obtainable (3 stars or less).

\section{Data Extraction}

In the fourth stage, selected studies were grouped according to the specified kidney disease outcome(s) under investigation characterizing the study population. To conduct the in-depth systematic review, the following information was extracted and registered from each article in a preset data extraction form: authors, publication year, country where the study is realized, study period, study population, type of study, $\mathrm{PM}_{2.5}$ exposure measurements, kidney dysfunction or parameters investigated, comorbidity at onset of the study (e.g., diabetes mellitus), identified confounders, and main findings (e.g., incidence rate of kidney disease outcome(s) in relation to $\mathrm{PM}_{2.5}$ exposure).

\section{Synthesis of Results}

The diversity in the examined human populations (e.g., the elderly, pregnant women, or general adult population) and differently defined assessments of kidney disease outcomes (e.g., using only one, two, or more eGFR measurements to determine CKD) did not allow to carry out a comparative quantitative analysis. Alternatively, we provided a qualitative overview of the results describing the effects of $\mathrm{PM}_{2.5}$ exposure on human kidney disease outcomes. The narrative synthesis of results was subsequently achieved by summarizing and grouping information on different kidney disease outcomes in relation to $\mathrm{PM}_{2.5}$ exposure.

\section{Results}

\section{Literature Selection and Assessment of Risk of Bias}

The last search was conducted on December $20^{\text {th }}, 2021$ using the MeSH terms "kidney" and "kidney disease", and the aforementioned additional keywords to identify 737 articles in total. Also, two new articles were identified from reference lists of reviews (Fig. 1). After the removal of duplicates, 587 articles remained and were screened for eligibility. The abstracts of these 587 articles were evaluated and 517 records were excluded from the analysis. From the total of excluded records, 32 articles were not written in English, 140 articles did not focus on ambient $\mathrm{PM}_{2.5}$ specifically, and 146 did not address the kidney or kidney disease outcomes. Additionally, 199 articles were excluded from the analysis as they did not address original studies $(\mathrm{n}=58)$, focused on experimental studies in animals or humans $(n=99+29=128)$, or did not address adults $(\mathrm{n}=13)$. The remaining 70 selected studies underwent in-depth review, resulting in 30 additional removals ( 3 articles lacked full-text availability, 10 were reviews, 12 were not original reports, and 5 addressed kidney cancer). The 40 studies fulfilling the inclusion criteria were included for this systematic review.

The risk of bias analysis was performed using the Newcastle - Ottowa Scale and articles were ranked accordingly: gaining $\leq 3$ stars meant a high risk of bias, $\leq 5$ stars an intermediate risk of bias, and $\geq 6$ stars a low risk of bias [20]. One article had an intermediate risk of bias [21], while no articles were considered as high risk of bias (Supplementary Table 1).

\section{Study Characteristics}

The 40 studies included in this systematic review were either cohort studies ( $\mathrm{n}=27$, Table 1$)$, cross-sectional ( $\mathrm{n}$ $=10$, Table 2$)$, ecological $(n=1$, Table 3$)$, or a time-series study $(\mathrm{n}=2$, Table 3$)$ and conducted in an epidemiological context of exposure to ambient $\mathrm{PM}_{2.5}$. We identified studies investigating (i) clinical measurements of the estimated glomerular filtration rate $(\mathrm{eGFR})(\mathrm{n}=8)[15,21-$ 27], (ii) general kidney functioning through changes in biomarkers $(\mathrm{n}=2)[28,29]$, and (iii) glomerular diseases $(\mathrm{n}=4)$ [30-32], including systemic lupus erythematosus (SLE; $\mathrm{n}=1$ ) [33]. The remaining 26 articles focused on persons with a diagnosis of diabetes mellitus $(n=2)$ $[34,35]$, the development and/or worsening of CKD $(\mathrm{n}=$ 14) [36-49], ESRD $(n=2)[50,51]$, renal failure $(n=4)$ [52-55], and kidney transplant outcome $(\mathrm{n}=4)(\mathrm{Fig} .2)$ [56-59].

Of all included studies, 19 studies [22-26, 31, 33-45, $47-53,56,58]$ had $\mathrm{PM}_{2.5}$ exposure levels that exceeded the old 2006 WHO air quality guidelines for ambient $\mathrm{PM}_{2.5}$, namely the annual mean $\left(10 \mu \mathrm{g} / \mathrm{m}^{3}\right)$ or the 24-hour mean $\left(25 \mu \mathrm{g} / \mathrm{m}^{3}\right)$ [60], of which 7 studies had $\mathrm{PM}_{2.5}$ exposure levels ranging from below the guideline to exceeding the pre-set guidelines $[33,34,36,44$, $51,56,58]$. Only 5 studies had a mean $\mathrm{PM}_{2.5}$ exposure level below the $2006 \mathrm{WHO}$ air quality guidelines [27, 54, $55,57,59]$. According to the new air quality guidelines announced in 2021, all studies exceeded the newly set guidelines for the annual mean $\left(5 \mu \mathrm{g} / \mathrm{m}^{3}\right)$ or the 24-hour mean $\left(15 \mu \mathrm{g} / \mathrm{m}^{3}\right)$ [10]. Additionally, 8 studies listed average $\mathrm{PM}_{2.5}$ exposure levels divergent from annual or daily means $\left[15,21,24,28-30,32,35\right.$, 46], i.e., 72 -hour $\mathrm{PM}_{2.5}$ exposure means [21], various moving day averages [24] two-year [46], three-year [30] or seven-year [50] annual $\mathrm{PM}_{2.5}$ means, $\mathrm{PM}_{2.5}$ means during the study or follow-up period [32, 35], and means of $\mathrm{PM}_{2.5}$ exposure during the pregnancy [15]. 


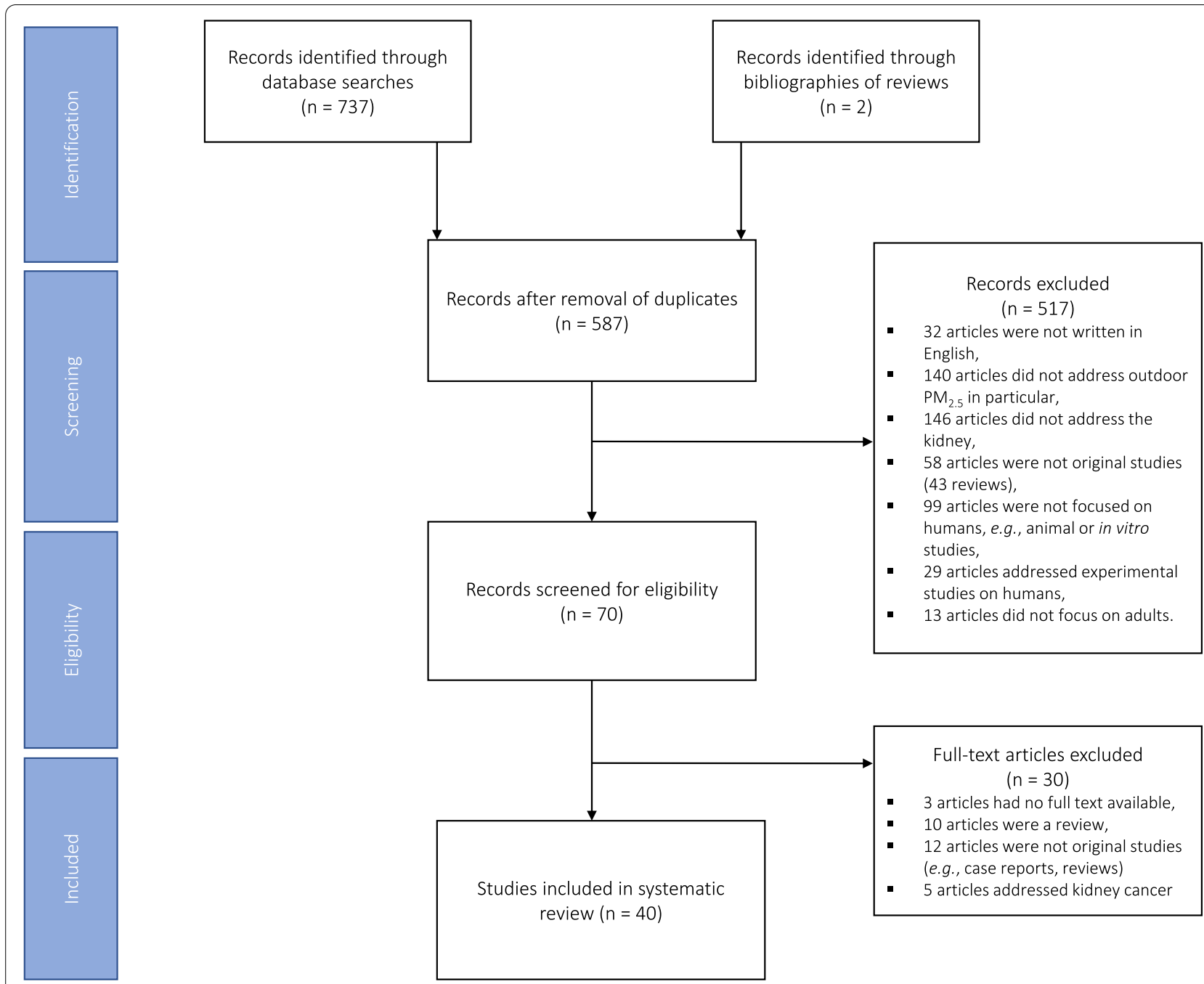

Fig. 1 Overview of the data selection process. Records either identified through database searches of PubMed and Scopus ( $n=737$ ) from January 1st, 2000 until December 20th, 2021, and records identified through bibliographies of reviews $(n=2)$. After checking for and removal of duplicates, records were screened for eligibility according to the a priori defined criteria, that resulted in $n=70$ eligible records. Next, full-text articles were screened for a second time against the eligibility criteria. The final selection $(n=40)$ consisted of human studies focusing on ambient PM exposure and addressing: (i) clinical measurements of eGFR $(n=8)$, (ii) general kidney function through changes in biomarkers $(n=2)$, and (iii) glomerular diseases $(n=4)$. The remaining articles focused on persons with a diagnosis of diabetes mellitus where kidney function declined $(n=2)$, CKD $(n$ $=14)$, ESRD $(n=2)$, renal failure $(n=4)$, and kidney transplant outcome $(n=4)$. Abbreviations: CKD, chronic kidney disease; ESRD, end-stage renal disease; eGFR, estimated glomerular filtration rate; $\mathrm{PM}_{2.5}$, fine particulate matter ( $<2.5$ microns)

Furthermore, 27 of the 40 included studies showed significant results or associations with investigated parameters and $\mathrm{PM}_{2.5}$ exposure $[15,21,23,26,30-32,34-37$, $39,40,43-54,58,59] ; 4$ studies did not show any significant results or associations $[24,25,42,56]$. It is of note that some articles $(\mathrm{n}=9)[22,27,28,33,38,40,55,57$, 59] showed significant associations with one parameter, but not with another parameter investigated. Blum et al. [22] observed no significant association in eGFR, but did observe significant associations with an increased risk of incident CKD and higher levels of albuminuria. Gao et al. [27] showed that ambient $\mathrm{PM}_{2.5}$ exposure could be associated with a decline in eGFR, but not to serum uric acid, blood urea nitrogen or odds of developing CKD. Chang et al. [57] could not observe associations with higher odds of acute kidney rejection in the lowest quartile of $\mathrm{PM}_{2.5}$ exposure, but in could in the highest quartile. Chuang et al. [28] showed differences in urinary markers for welders post-exposure, but could not find significant differences in office workers post-exposure. Bernatsky et al. [33] showed no associations between $\mathrm{PM}_{2.5}$ exposure and the overall measurement to score systemic lupus erythematosus disease activity, but anti-double stranded DNA and urinary casts could be significantly associated 


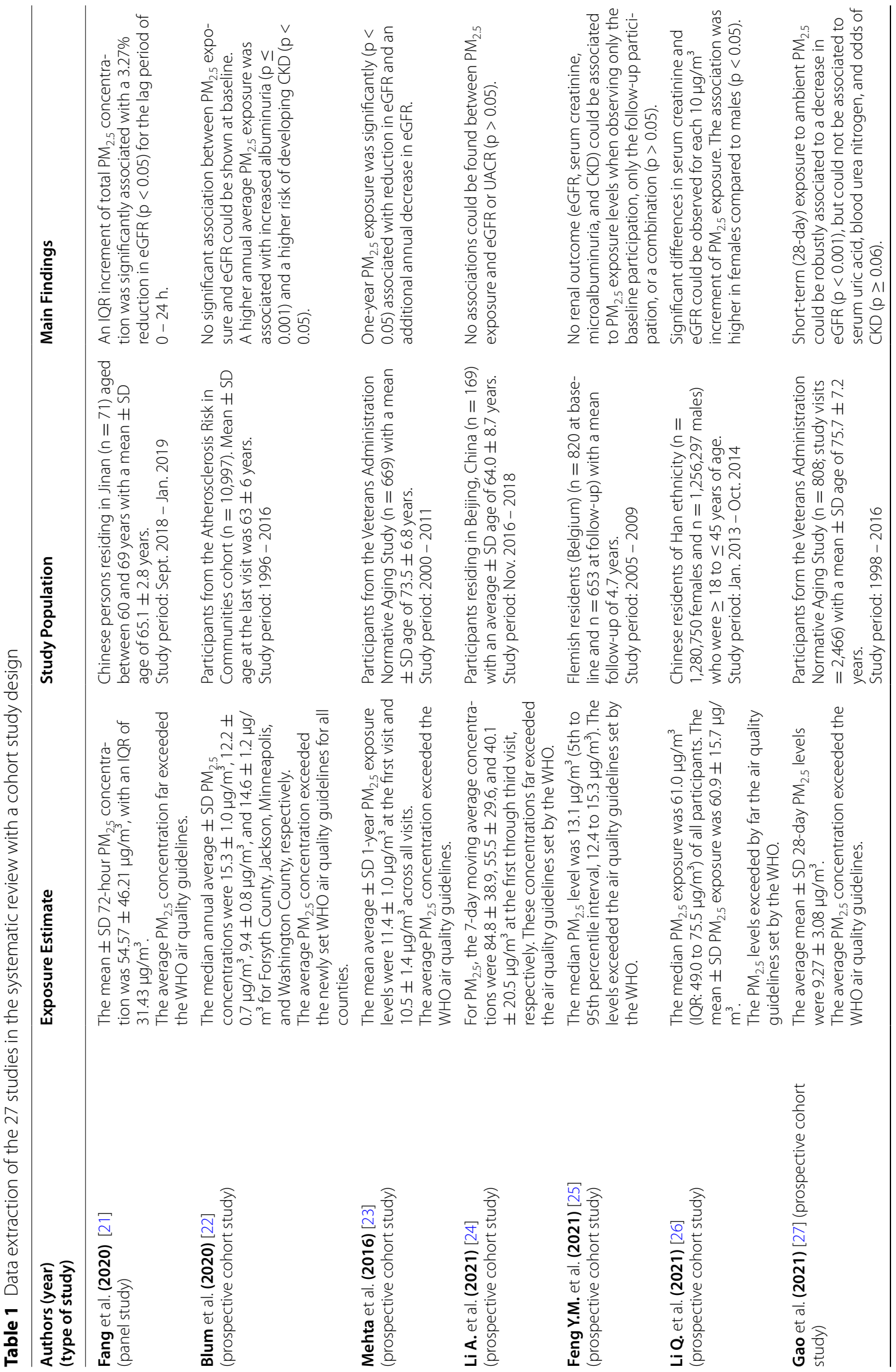




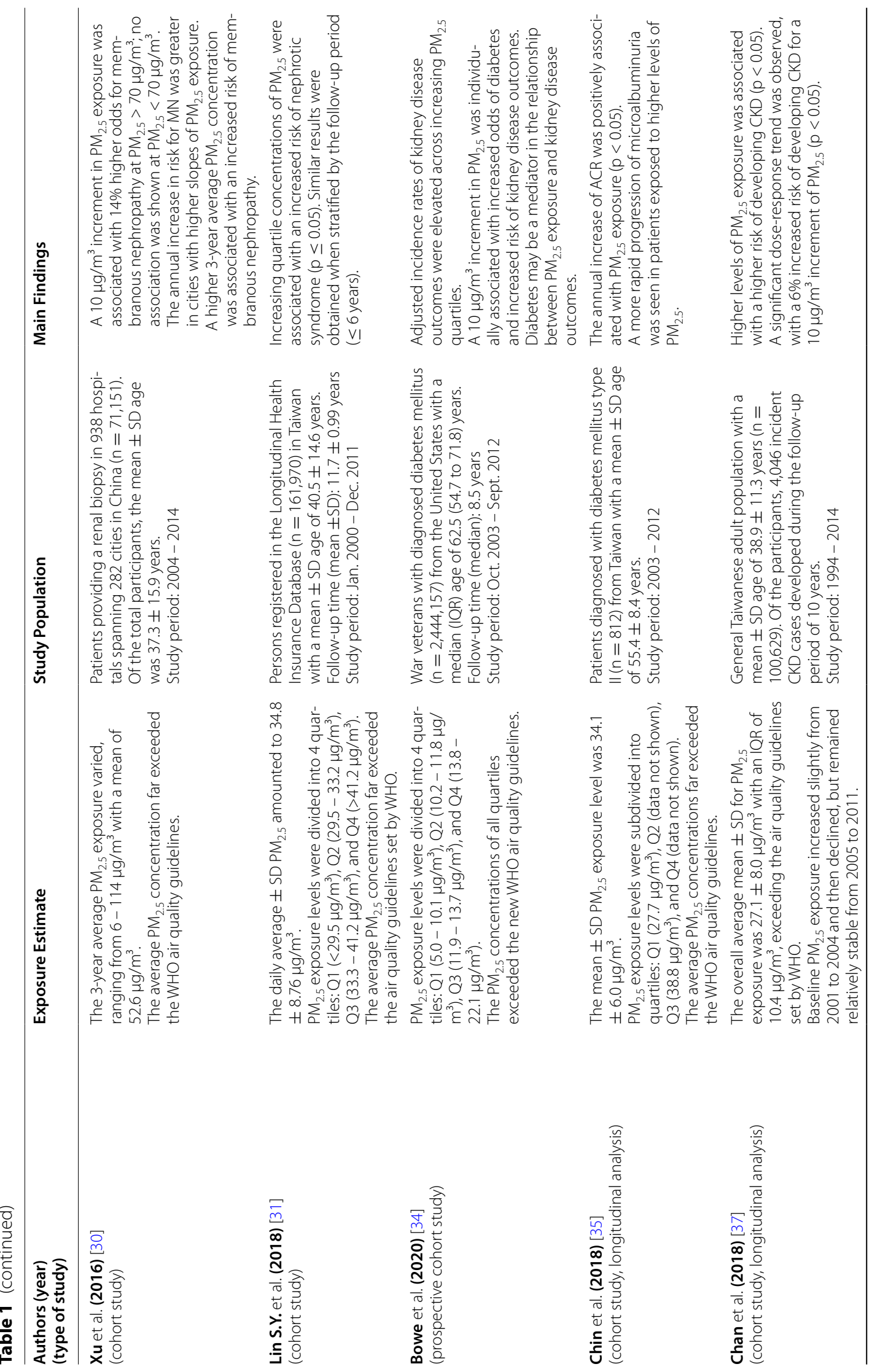




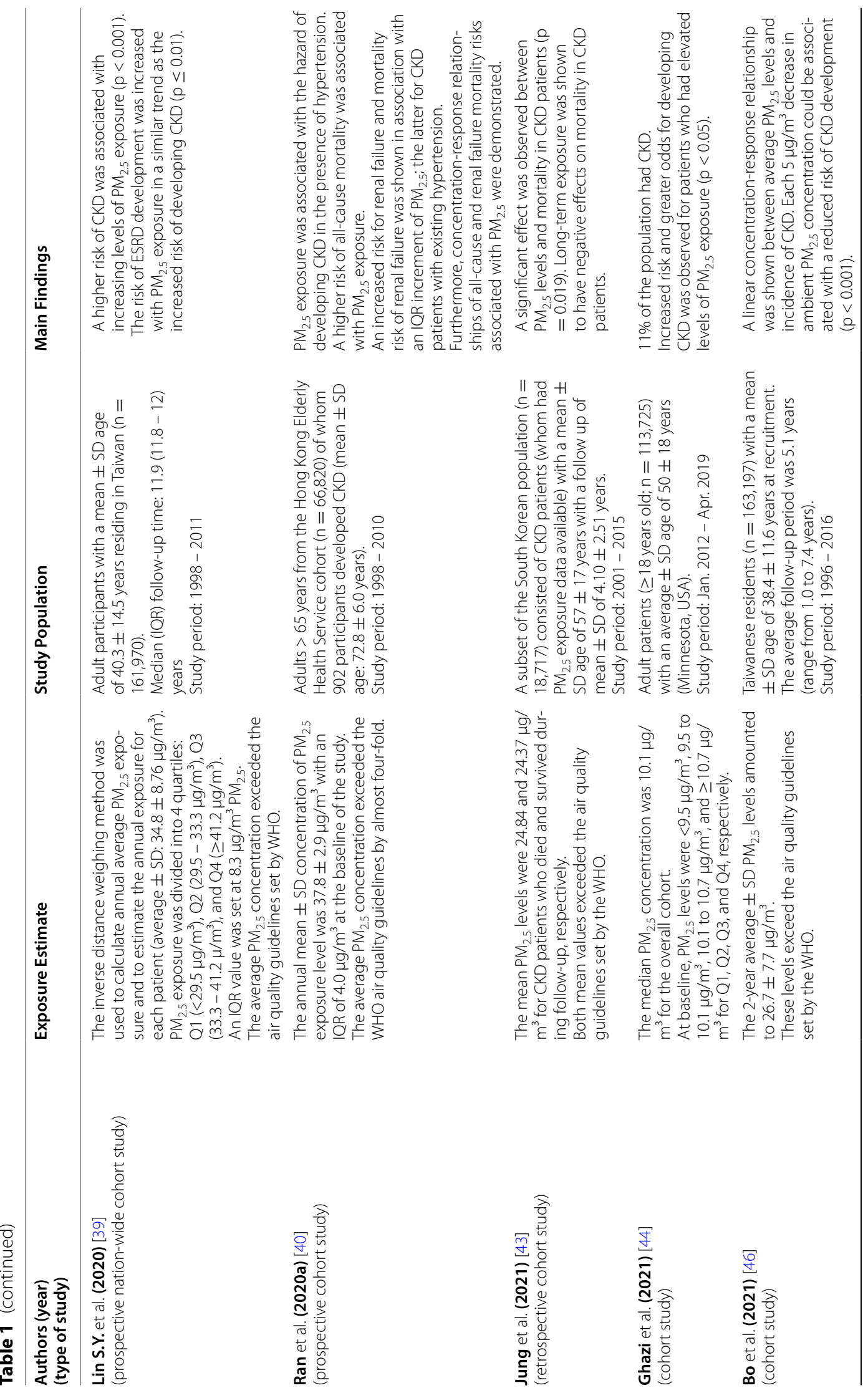




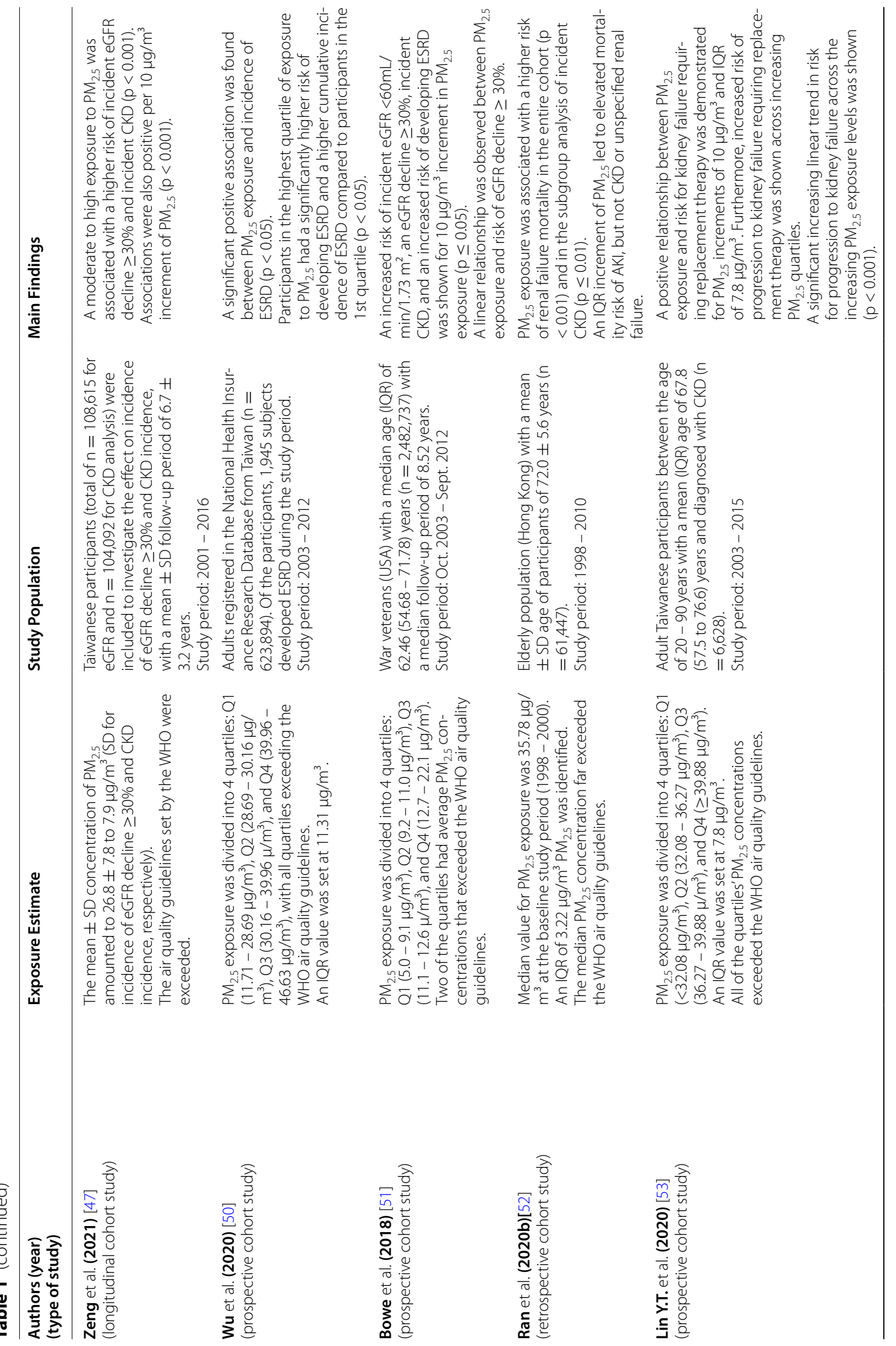




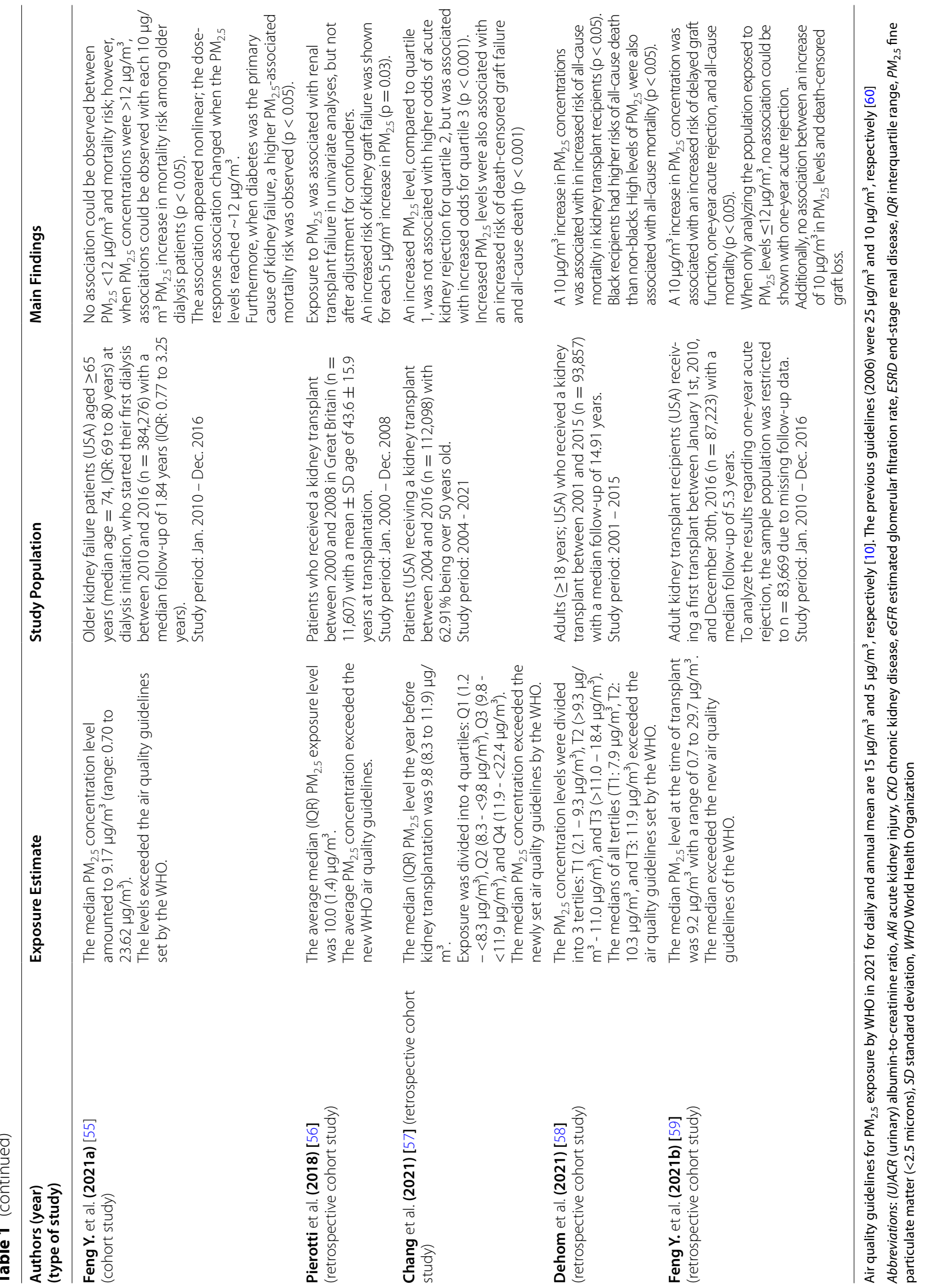




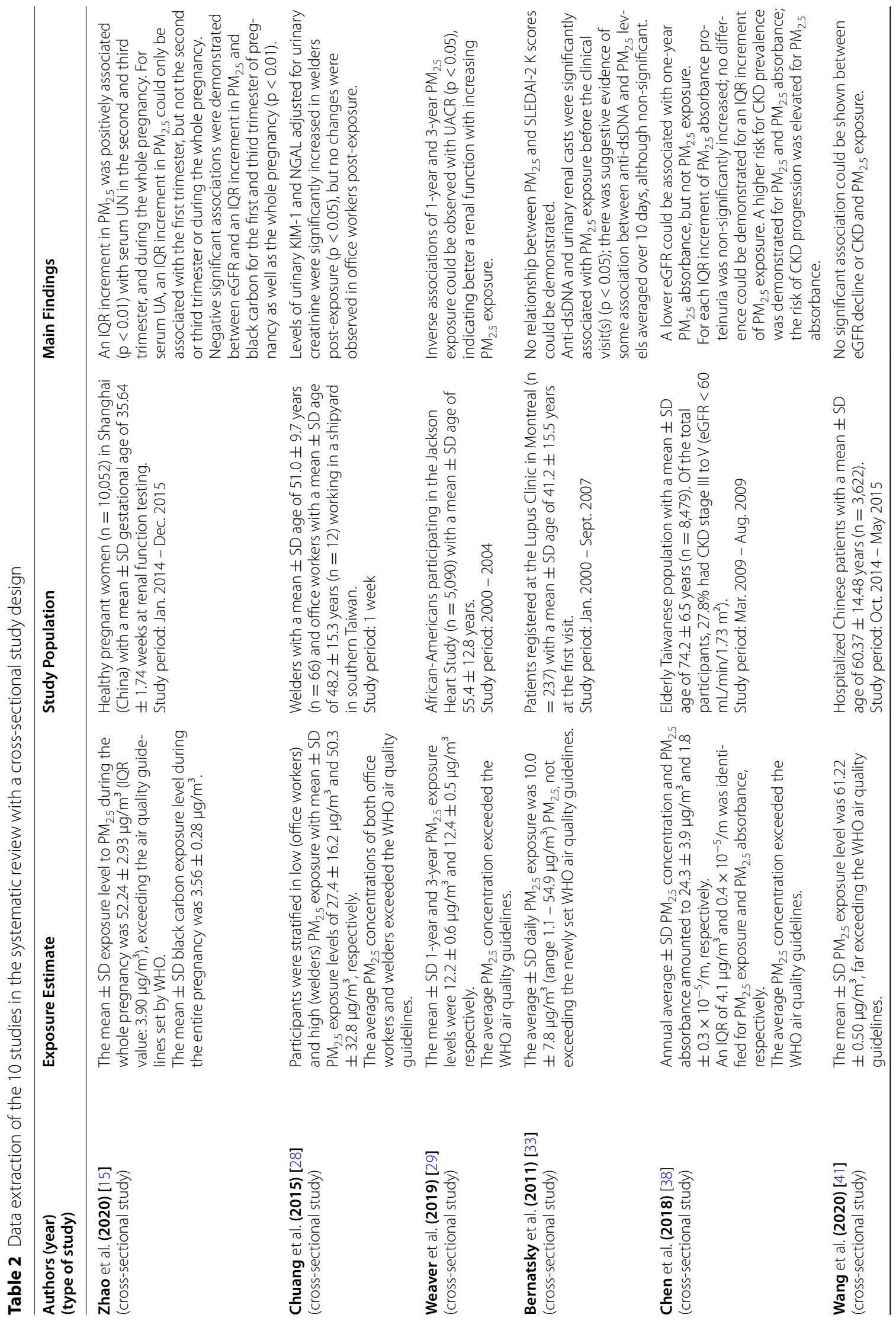




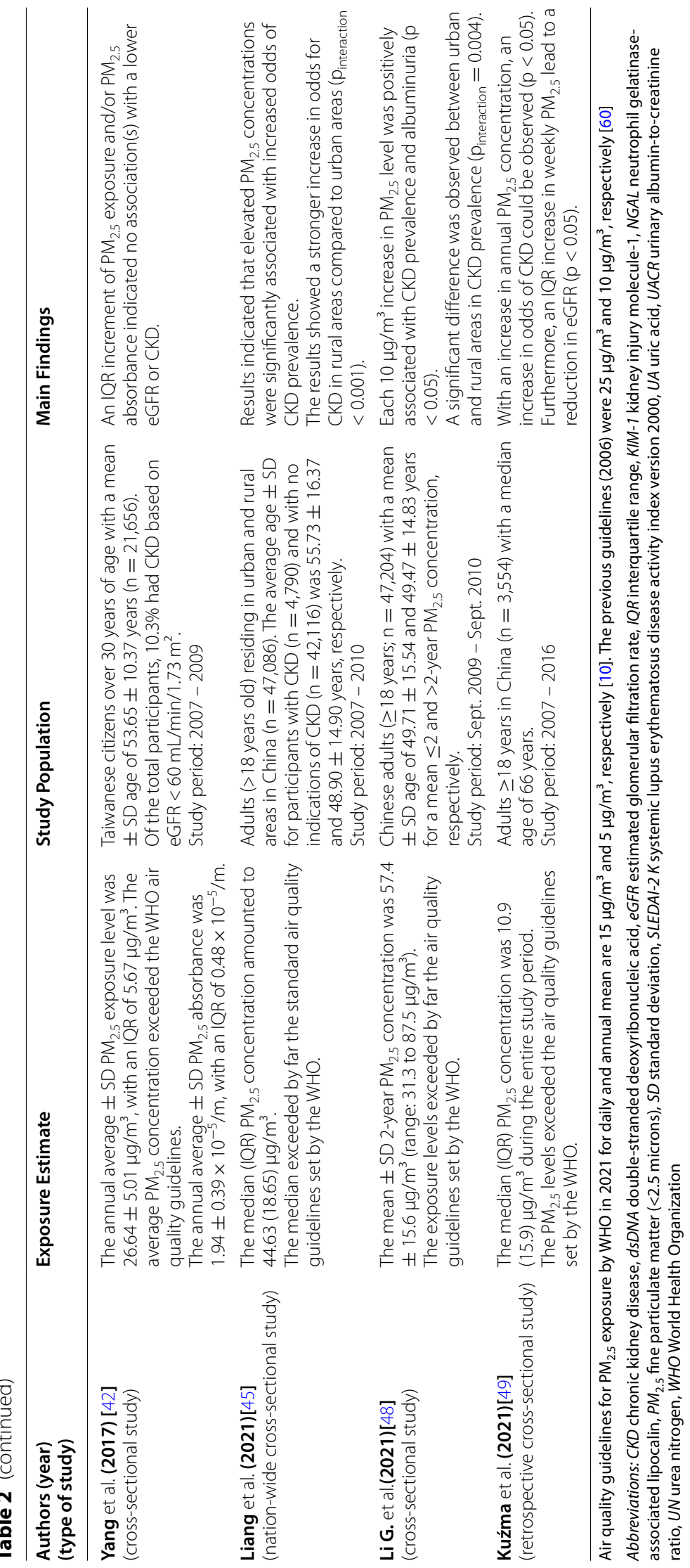




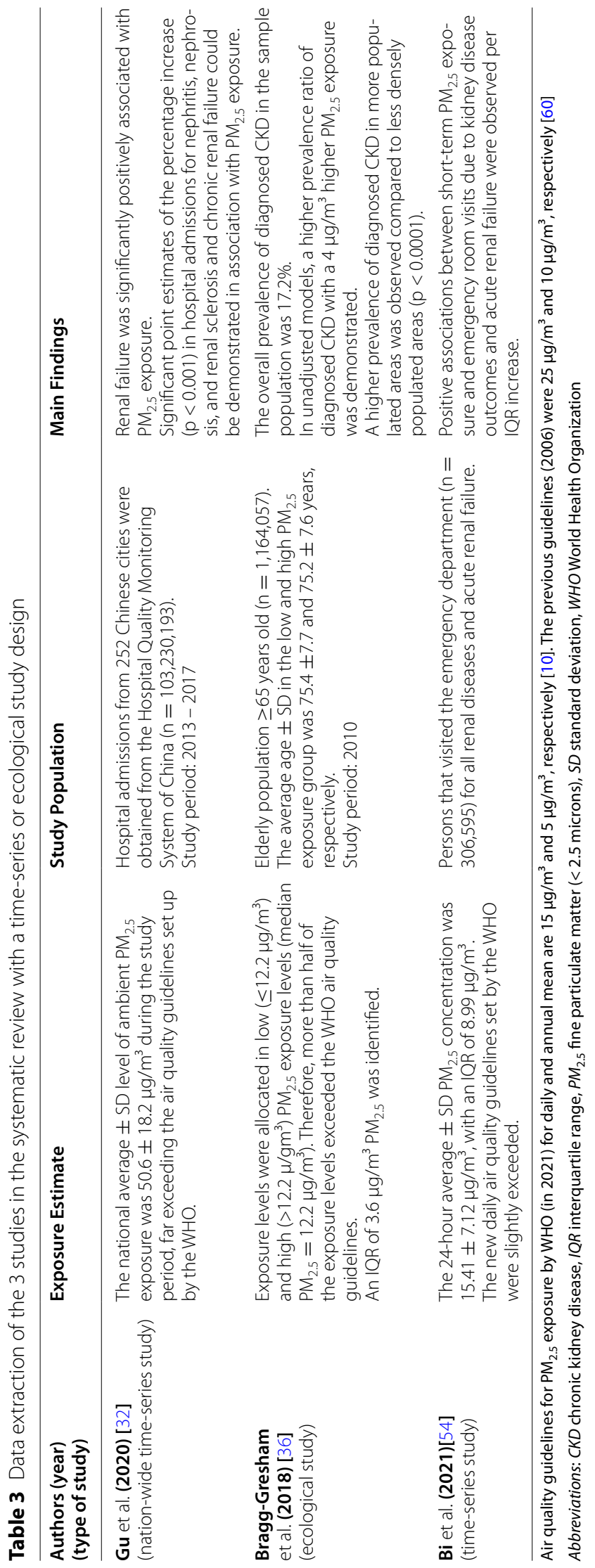




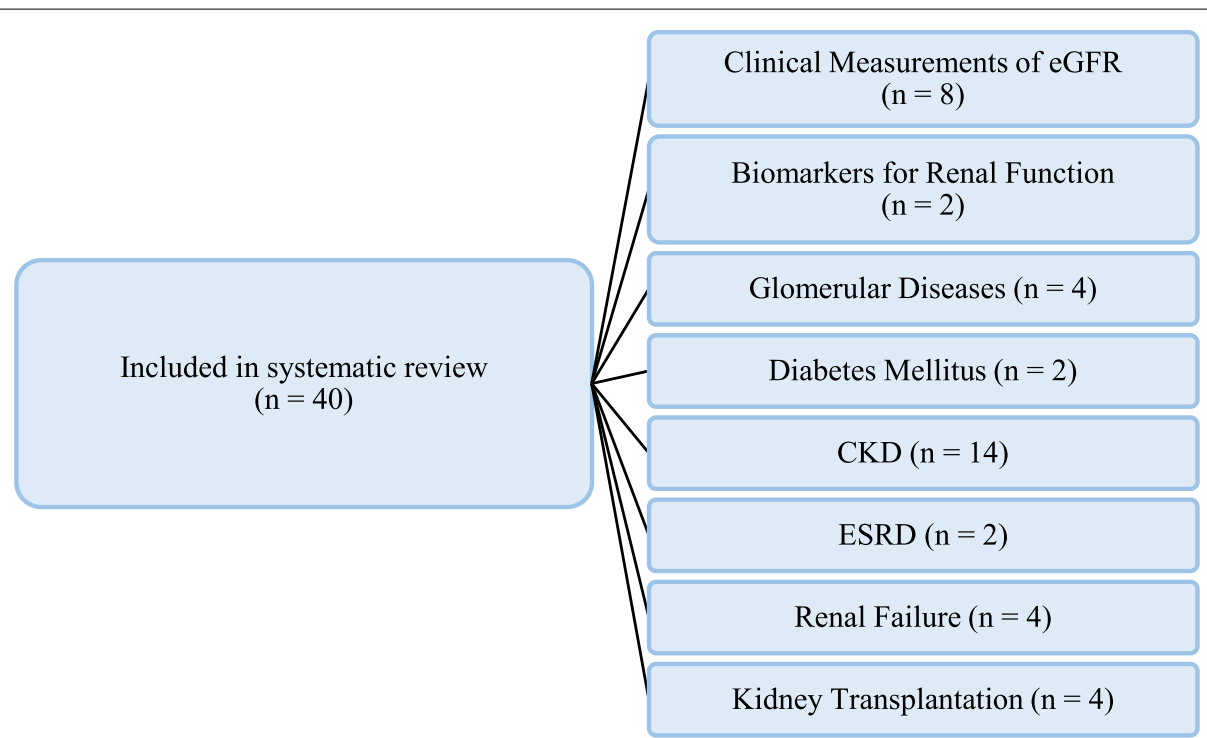

Fig. 2 Schematic overview of the distribution of articles on kidney disease (outcomes) in the systematic review. Eligible articles $(n=40)$ were divided into the corresponding disease outcomes. Included studies focused on (i) clinical measurements of eGFR ( $n=8$ ), (ii) biomarkers to evaluate kidney function following PM exposure $(n=2)$, (iii) glomerular diseases $(n=4)$, (iv) diabetes mellitus as a driver to kidney function decline $(n=2)$, (v) CKD ( $n=14)$, (vi) ESRD ( $n=2)$, (vii) kidney failure $(n=4)$, and (viii) kidney transplantation $(n=4)$. These numbers of articles for the listed classes of kidney disease (outcomes) do not necessarily correspond with the main text, as for each class, the most representative articles were considered. Abbreviations: CKD, chronic kidney disease; ESRD, end-stage renal disease; eGFR, estimated glomerular filtration rate; $\mathrm{PM}_{2.5}$, fine particulate matter $(<2.5$ microns $)$

to $\mathrm{PM}_{2.5}$ exposure. No differences in eGFR could be demonstrated for $\mathrm{PM}_{2.5}$ exposure, but Chen et al. [38] could for $\mathrm{PM}_{2.5}$ absorbance. Feng Y. and colleagues [55] could not show an association between mortality risk in dialysis patients and low levels of $\mathrm{PM}_{2.5}\left(<12 \mu \mathrm{g} / \mathrm{m}^{3}\right)$, but did show associations for exposure to levels $\geq 12 \mu \mathrm{g} / \mathrm{m}^{3}$. Similar results were seen regarding $\mathrm{PM}_{2.5}$ exposure of kidney transplant recipients [59], where no association with one-year acute rejection could be shown below $12 \mu \mathrm{g} / \mathrm{m}^{3}$ $\mathrm{PM}_{2.5}$ exposure; though, associations were demonstrated with an increased risk of delayed graft function one-year acute rejection and all-cause mortality for each $10 \mu \mathrm{g} / \mathrm{m}^{3}$ increase in $\mathrm{PM}_{2.5}$ exposure. Lastly, Ran et al. [40] found that $\mathrm{PM}_{2.5}$ exposure was associated with renal failure mortality among hypertensive patients, but could not show associations with e.g., all-cause mortality among CKD patients.

\section{Discussion}

\section{eGFR for Assessment of Renal Function}

The estimated glomerular filtration rate (eGFR) describes the filtration of a certain volume of blood (milliliter) per unit of time (minutes) for a corporal surface of $1.73 \mathrm{~m}^{2}$ by the glomerular capillaries into Bowman's capsules. Despite that the gold standard for GFR evaluation is the measurement of inulin clearance, eGFR is currently used in medical practice to assess kidney function changes [61]. In the clinic, the GFR is estimated according to the Chronic Kidney Disease-Epidemiology Collaboration (CKD-EPI) equation. The single CKD-EPI equation for estimating GFR is eGFR $=141 \times \min$ (serum creatinine $/ \kappa, 1)^{\alpha} \times \max (\text { serum creatinine } / \kappa, 1)^{-1.209}$ $\times 0.993^{\text {Age }} \times 1.018$ [if female] $\times 1.159$ [if black], where serum creatinine is expressed in $\mathrm{mg} / \mathrm{dL}, \mathrm{\kappa}$ is 0.7 for females and 0.9 for males, and $\alpha$ is -0.329 for females and -0.411 for males [62]. Another method to estimate GFR, used commonly and addressed by various articles in this review is the Modification of Diet in Renal Disease $($ MDRD) equation: eGFR $=175 \times$ (serum creatinine $)^{-1.154} \times(\text { age })^{-0.203} \times 0.742$ [if female] $\times 1.212$ [if black], where serum creatinine is expressed in $\mathrm{mg} / \mathrm{dL}$ [63].

The effects of $\mathrm{PM}_{2.5}$ exposure on changes in eGFR was addressed in 12 of the included studies [15, 21-27, $42,47,49,51]$. These studies evaluating $\mathrm{PM}_{2.5}$ and eGFR have shown contradictory results. In the Atherosclerosis Risk in Communities cohort, participants were followed up from 1996 to 1998 to 2016 (mean age 63 years; $\mathrm{n}=10,997$ ); at baseline, no significant association between $\mathrm{PM}_{2.5}$ exposure and eGFR [eGFR $=0.07$ $\mathrm{mL} / \mathrm{min} / 1.73 \mathrm{~m}^{2}, 95 \%$ confidence interval (CI) -0.28 to 0.41$]$ was found [22]. In a cross-sectional study conducted on citizens ( $>30$ years; $n=21,656$ ), Yang et al. [42] showed no significant association in eGFR decline 
$\left(\mathrm{eGFR}=-0.09 \mathrm{~mL} / \mathrm{min} / 1.73 \mathrm{~m}^{2}, 95 \% \mathrm{CI}-0.25\right.$ to 0.07$)$ for an interquartile range (IQR) increment of $5.67 \mu \mathrm{g} /$ $\mathrm{m}^{3}$ in $\mathrm{PM}_{2.5}$. Furthermore, the latter report also did not show a significant association between change in eGFR $\left(0.02 \mathrm{~mL} / \mathrm{min} / 1.73 \mathrm{~m}^{2}, 95 \% \mathrm{CI}-0.16\right.$ to 0.19$)$ and an IQR increment of $0.48 \times 10^{-5} / \mathrm{m}$ in $\mathrm{PM}_{2.5}$ absorbance, which characterizes local soot emissions [42]. In a Flemish cohort $(n=820$ at baseline participation and $n=653$ at follow-up participation), Feng Y.M. et al. [25] stipulated that changes in eGFR [Odds ratio $(\mathrm{OR})_{\text {baseline }}=0.00$, 95\% CI -1.18 to $1.19 ; \mathrm{OR}_{\text {follow-up }}=-0.30,95 \% \mathrm{CI}-1.78$ to 1.18 ; and $\mathrm{OR}_{\text {combination }}=0.01,95 \% \mathrm{CI}-1.16$ to 1.17 ] or serum creatinine $\left(\mathrm{OR}_{\text {baseline }}=0.23,95 \% \mathrm{CI}-1.07\right.$ to 1.52 ; $\mathrm{OR}_{\text {follow-up }}=0.10,95 \% \mathrm{CI}-2.03$ to 2.23 ; and $\mathrm{OR}_{\text {combination }}$ $=0.28,95 \% \mathrm{CI}-1.19$ to 1.75$)$ were unrelated to $\mathrm{PM}_{2.5}$ exposure $(p \geq 0.69)$ when considering only the baseline exposure levels, only the follow-up, or a combination. Lastly, Li A. et al. [24] investigated the effects of $\mathrm{PM}_{2.5}$ exposure on eGFR in a population $(n=169)$ residing in China. A decline in eGFR, calculated through both the MDRD (e.g., 60-day exposure: $2.78 \%, 95 \%$ CI -4.61 to 10.73) and CKD-EPI (e.g., 60-day exposure: 1.05\%, 95\% CI -2.51 to 4.75 ) equations, was inversely associated with each IQR increase in $\mathrm{PM}_{2.5}$ concentrations, albeit nonsignificant $(\mathrm{p}>0.05)$.

However, in a prospective cohort study on young adults aged 18 to 45 years $(n=2,546,047)$ of Han ethnicity, $\mathrm{Li}$ Q. et al. [26] observed a $0.77 \%$ decrease in eGFR (95\% CI -0.81 to $-0.73 ; \mathrm{p}<0.05)$ for each $10 \mu \mathrm{g} / \mathrm{m}^{3}$ increment in $\mathrm{PM}_{2.5}$ exposure. Additionally, for each $10 \mu \mathrm{g} / \mathrm{m}^{3} \mathrm{PM}_{2.5}$ increment, a significant increase of $0.87 \%$ (95\% CI 0.82 to 0.91; $\mathrm{p}<0.05)$ in serum creatinine could be shown [26]. Furthermore, associations between eGFR or serum creatinine and $\mathrm{PM}_{2.5}$ exposure levels were higher in females than in males $(\mathrm{p}<0.05)$. In another a prospective cohort study on war veterans (mean age 73.5 years at the first visit; $\mathrm{n}=669$ ), Mehta et al. [23] showed that a $2.1 \mu \mathrm{g} / \mathrm{m}^{3}$ higher one-year $\mathrm{PM}_{2.5}$ exposure was significantly associated $(\mathrm{p}<0.05)$ with a $1.87 \mathrm{~mL} / \mathrm{min} / 1.73 \mathrm{~m}^{2}$ lower eGFR (95\% CI -2.99 to -0.76 ); additionally, the aforementioned increment in one-year $\mathrm{PM}_{2.5}$ was significantly associated $(\mathrm{p}<0.05)$ with an annual decrease in eGFR of $0.60 \mathrm{~mL} /$ $\mathrm{min} / 1.73 \mathrm{~m}^{2}$ (95\% CI -0.79 to -0.40$)$. They could not only link $\mathrm{PM}_{2.5}$ to a reduced eGFR, but also to an increased rate of eGFR decline over time [23]. A second study [27] performed on this population assessed the short-term (28-day window) effects of $\mathrm{PM}_{2.5}$ exposure on renal function. The average \pm SD 28-day $\mathrm{PM}_{2.5}$ concentration was $9.27 \mu \mathrm{g} / \mathrm{m}^{3} \pm 3.08 \mu \mathrm{g} / \mathrm{m}^{3}$ to which the 808 elderly war veterans with a mean \pm SD age of $75.7 \pm 7.2$ years $(\mathrm{n}$ $=2,466$ study visits over those 808 participants) were exposed. Results indicated a robust association between $\mathrm{PM}_{2.5}$ exposure and lower eGFR. For each $4.09 \mu \mathrm{g} / \mathrm{m}^{3}$ increment in 28-day $\mathrm{PM}_{2.5}$, a mean \pm standard error (SE) change of $-1.6078 \pm 0.4446 \mathrm{~mL} / \mathrm{min} / 1.73 \mathrm{~m}^{2}$ was observed $(\mathrm{p}<0.001)$.

A retrospective cross-sectional study by Kuźma et al. [49] on patients, referred for elective coronary angiography $(\mathrm{n}=3,554)$ with a median age of 66 years, showed that a $15.9 \mu \mathrm{g} / \mathrm{m}^{3}$ increase in weekly $\mathrm{PM}_{2.5}$ exposure was associated with a $2 \%$ reduction in expected eGFR $(\beta=0.02,95 \%$ CI -0.03 to $-0.01 ; p<0.05)$. In another cross-sectional study design on pregnant women $(\mathrm{n}=$ 10,052), Zhao et al. [15] estimated a significant reduction $(\mathrm{p}<0.01)$ in eGFR of $0.54 \mathrm{~mL} / \mathrm{min} / 1.73 \mathrm{~m}^{2}$ (95\% CI -0.74 to -0.33) during the entire pregnancy for an IQR increment of $\mathrm{PM}_{2.5}$. In a prospective war veterans study $(\mathrm{n}=$ 2,482,737), Bowe et al. [51] reported an increased risk ( $\mathrm{p} \leq 0.05$ ) of incident eGFR $<60 \mathrm{~mL} / \mathrm{min} / 1.73 \mathrm{~m}^{2}$ [hazard ratio $(\mathrm{HR})=1.25,95 \%$ CI 1.17 to 1.34 ] for a $10 \mu \mathrm{g} / \mathrm{m}^{3}$ increment in $\mathrm{PM}_{2.5}$. Compared to participants exposed to lower $\mathrm{PM}_{2.5}$ levels $\left(5.0-9.1 \mu \mathrm{g} / \mathrm{m}^{3}\right)$, participants exposed to higher $\mathrm{PM}_{2.5}$ levels $\left(>9.2 \mu \mathrm{g} / \mathrm{m}^{3}\right)$ had a gradually increased risk of incident eGFR $<60 \mathrm{~mL} / \mathrm{min} / 1.73 \mathrm{~m}$ [51]. In addition, in a general adult Taiwanese population $(\mathrm{n}=108,615)$ with an average \pm SD age of $39.1 \pm 11.8$ years, Zeng et al. [47] demonstrated that each $10 \mu \mathrm{g} / \mathrm{m}^{3}$ increment of $\mathrm{PM}_{2.5}$ could be significantly associated ( $\mathrm{p}<$ 0.001 ) with a 3.18 -fold increased risk of an eGFR decline $\geq 30 \%$ (95\% CI 2.88 to 3.50 ). In an elderly population (60 -69 years old; $\mathrm{n}=71$ ), the panel study of Fang et al. [21] showed that an IQR increment of $31.43 \mu \mathrm{g} / \mathrm{m}^{3}$ in $\mathrm{PM}_{2.5}$ exposure was significantly associated $(\mathrm{p}<0.05)$ with a $3.27 \%$ eGFR decrease, albeit in a small population size ( $\mathrm{n}$ $=71$ ).

The underlying mechanism(s) that may explain why 4 studies [22, 24, 25, 42] showed no association, while 8 other studies $[15,21,23,26,27,47,49,51]$ did show associations between a decline in eGFR and $\mathrm{PM}_{2.5}$ exposure, remain unexplored. Yet, as $\mathrm{PM}_{2.5}$ components vary by region, certain regions may contain higher concentrations of such components that are more detrimental to glomerular and proximal tubular function leading to differences in eGFR measurements [15, 22, 23]. However, it is of note that Mehta et al. [23], Gao et al. [27], Zhao et al. [15], and Bowe et al. [51] investigated overall kidney function on distinctive subpopulations, i.e., elderly veterans with a mean age of 73.5 years [23] and 75.7 years [27] respectively, Chinese pregnant women [15], and veterans with a median age of 62.5 years [51], which are not representative for the general population, in contrast to the studies by Fang et al. [21], Blum et al. [22], Feng Y.M. et al. [25], Li A. et al. [24], Li Q. et al. [26], Kuźma et al. [49], Zeng et al. [47], and Yang et al. [42]. In addition, the GFR in normal pregnancies can increase 40 to $50 \%$; therefore, the current standard in clinical practices 
to evaluate glomerular filtration rate is the creatinine clearance in 24-hour urine [64]. Zhao et al. [15] measured serum creatinine but did not describe any changes in creatinine clearance in relation to $\mathrm{PM}_{2.5}$ exposure.

It is of note that not all studies use the same equation to determine eGFR. Of all studies addressing measurement(s) of eGFR in this review, 5 studies [21, 43, 46-48] estimated GFR according to the MDRD equation, one study [51] did not specify, and one study [24] used both equations to estimate GFR, while 13 studies [22, 23, 25-27, 29, 34, 37, 38, 41, 42, 44, 49] used the CKD-EPI equation to determine eGFR. Current research is contradictory about the superiority of either methods to estimate GFR [38, 62, 65, 66]. However, in 2013, the CKD-EPI equation was recommended by the 'Kidney Disease: Improving Global Outcomes (KDIGO) to estimate GFR [67].

\section{Evaluation of Renal Function through Biomarkers in Urine and Blood}

In addition to the use of eGFR measurements and creatinine clearance in the routine assessment of kidney function, urinary biomarkers are progressively used as a noninvasive tool to evaluate the glomerular and tubular functions of the kidneys.

Albuminuria is a sensitive, prognostic marker for changes that are observed in the glomerulus and its permeability to macromolecules [68]. Five studies focused on albuminuria after $\mathrm{PM}_{2.5}$ exposure [22, 24, 25, 29, 48]. $\mathrm{Li}$ G. et al. [48] demonstrated that each $10 \mu \mathrm{g} / \mathrm{m}^{3}$ increment of $\mathrm{PM}_{2.5}$ exposure could be positively associated $(\mathrm{OR}=1.39,95 \%$ CI 1.32 to 1.47$)$ with albuminuria $(\mathrm{p}<$ $0.001)$ in an adult Chinese population $(n=47,204)$. The study by Blum and colleagues [22] showed that a higher annual average $\mathrm{PM}_{2.5}$ exposure was associated with increased albuminuria. They concluded that a $1 \mu \mathrm{g} / \mathrm{m}^{3}$ increment of the annual average $\mathrm{PM}_{2.5}$ was significantly associated ( $\mathrm{p} \leq 0.001)$ with a higher urinary albumincreatinine ratio (UACR) (6.6\% difference, $95 \%$ CI 2.6 to 10.7\%) [22]. The cross-sectional study design of Weaver et al. [29] has shown opposite results, including inverse associations $(\mathrm{p}<0.05)$ of UACR with 1-year and 3-year averaged $\mathrm{PM}_{2.5}$ exposure $(\mathrm{OR}=-0.09,95 \% \mathrm{CI}-0.2$ to -0.02 and $\mathrm{OR}=-0.2,95 \% \mathrm{CI}-0.3$ to -0.06 , respectively). The authors stated that this may be due to bias, since participants with better kidney function are more likely to provide urine samples when operating on a voluntary basis [29]. The study by Feng Y.M. et al. [25] showed that changes in microalbuminuria $\left(\mathrm{OR}_{\text {baseline }}=0.27,95 \% \mathrm{CI}\right.$ -0.26 to 0.79 ; $\mathrm{OR}_{\text {follow-up }}=0.06,95 \% \mathrm{CI}-0.43$ to 0.54 ; and $\mathrm{OR}_{\text {combination }}=0.21,95 \% \mathrm{CI}-0.19$ to 0.61$)$ were unrelated to $\mathrm{PM}_{2.5}$ exposure $(\mathrm{p} \geq 0.31)$ when considering only the baseline, only the follow-up, or a combination of participation ( $\mathrm{n}=820$ at the baseline participation and $\mathrm{n}=653$ at follow-up participation). Furthermore, in a small population sample $(n=169)$ of participants with an average \pm SD age of $64.0 \pm 8.7$ years, Li A. et al. [24] could not show any associations between an IQR increase in $\mathrm{PM}_{2.5}$ and UACR (e.g., 60-day exposure: 0.05\%, 95\% CI -0.50 to $0.61 ; \mathrm{p}>0.05)$.

Other promising markers include urinary kidney injury molecule-1 (KIM-1) [69] and neutrophil gelatinaseassociated lipocalin (NGAL) [28, 70], tubular markers of extracellular matrix receptor interaction [28, 70]. Using the urinary markers KIM-1 and NGAL, Chuang et al. [28] investigated the renal effects of exposure in welders and office workers in a cross-sectional study of whom the personal $\mathrm{PM}_{2.5}$ exposure $\left(50.3 \mu \mathrm{g} / \mathrm{m}^{3}\right.$ and $27.4 \mu \mathrm{g} /$ $\mathrm{m}^{3}$, respectively) exceeded the daily guideline set by the WHO at that time frame $\left(25 \mu \mathrm{g} / \mathrm{m}^{3}\right)$ [60]. Urinary levels of KIM-1 were significantly increased in welders postexposure compared to pre-exposure $(\mathrm{p}<0.05)$, but no difference was observed between post- and pre-exposure in office workers. Urinary NGAL was significantly higher $(\mathrm{p}<0.05)$ in welders as well as office workers post-exposure compared to pre-exposure. These results indicate that $\mathrm{PM}_{2.5}$ might negatively affect tubular kidney function during short periods of exposure (one working week between pre- and post-exposure measurements of the biomarkers) [28].

Other traditional biomarkers employed in medical practice include measurements of uric acid (UA) and urea nitrogen (UN) in blood. Increases in UA or $\mathrm{UN}$ are an indication of kidney function decline, due to a decrease in the glomerular filtration rate $[15,71]$. In pregnant women, Zhao et al. [15] demonstrated for a IQR increment of $3.90 \mu \mathrm{g} / \mathrm{m}^{3} \mathrm{PM}_{2.5}$ exposure increases of $0.05 \mathrm{mmol} / \mathrm{L}$ (95\% CI 0.04 to 0.07 ) in serum UN and 0.60 $\mathrm{mmol} / \mathrm{L}$ (95\% CI -0.86 to 2.06 ) in serum UA, indicating a reduction of eGFR. Whereas serum UN was found to be significantly positively associated $(\mathrm{p}<0.01)$ with $\mathrm{PM}_{2.5}$ during the whole pregnancy, no such association could be shown for serum UA [15]. Furthermore, Gao et al. [27] indicated that no significant associations $(\mathrm{p}>0.06)$ could be shown for UA $(0.0674 \mathrm{mg} / \mathrm{dL}$; SE: $0.0442 \mathrm{mg} / \mathrm{dL})$ and UN $(0.0110 \mathrm{mg} / \mathrm{dL}$; SE: $0.1987 \mathrm{mg} / \mathrm{dL})$ for each $4.09 \mu \mathrm{g} /$ $\mathrm{m}^{3}$ increase in short-term 28-day $\mathrm{PM}_{2.5}$ concentration.

The use of novel renal biomarkers in relation to $\mathrm{PM}_{2.5}$ exposure in a clinical setting remains largely underexplored. Various other well-documented urinary glomerular markers such as cystatin $C$ [72] and urinary tubular markers such as $\beta_{2}$-microglobulin [73], $\alpha_{1}$-microglobulin [74], and retinol-binding protein [75] have not been investigated in (large) population-based studies in relation to the early toxic effects of environmental $\mathrm{PM}_{2.5}$ exposure on kidney function. Further research is required 
to determine their potential both in research and clinical settings.

\section{Glomerular Diseases}

Glomerular diseases (e.g., glomerulonephritis, such as nephrotic syndrome) are caused by damage to the glomeruli, which may cause leakage of large proteins into the urine and interference with the clearance of waste products, which can result in a buildup of harmful substances in the blood. Four of the included studies addressed the effects of $\mathrm{PM}_{2.5}$ exposure on the glomeruli [30-32], of which one specifically addressed the auto-immune disorder systemic lupus erythematosus (SLE) [33].

In a time-series study on hospital admissions attributable to nephritis [32], a $10 \mu \mathrm{g} / \mathrm{m}^{3}$ increment in $\mathrm{PM}_{2.5}$ exposure caused a significant percental change of 0.23 (95\% CI 0.08 to $0.39 ; \mathrm{p}<0.05)$ in hospital admissions due to nephritis. The cohort study by Lin S.Y. et al. [31] demonstrated a clear dose-response relationship between $\mathrm{PM}_{2.5}$ exposure and nephrotic syndrome (NS) in a population cohort of residents of Taiwan ( $n=161,970)$. An increasing trend for risk of developing NS was shown; relative to the lowest $\mathrm{PM}_{2.5}$ exposure level (quartile $1 ;<29.5 \mu \mathrm{g} / \mathrm{m}^{3}$ ), the highest level of $\mathrm{PM}_{2.5}$ exposure (quartile $4 ;>41.2 \mu \mathrm{g} /$ $\mathrm{m}^{3}$ ) was associated with a 2.53-fold higher risk of developing NS (HR $=2.53,95 \%$ CI 1.01 to 5.94; $\mathrm{p}<0.05$ ) [31].

A common cause of NS in adults is idiopathic membranous nephropathy (iMN), where the immune system attacks the glomeruli, leading to kidney damage [76]. A cohort study by $\mathrm{Xu}$ et al. [30] demonstrated that higher $\mathrm{PM}_{2.5}$ exposure was associated with an increased risk of iMN. However, the relationship appeared non-linear below $\mathrm{PM}_{2.5}$ concentrations of $70 \mu \mathrm{g} / \mathrm{m}^{3}$; above $70 \mu \mathrm{g} / \mathrm{m}^{3}$, an increment of $10 \mu \mathrm{g} / \mathrm{m}^{3} \mathrm{PM}_{2.5}$ exposure was associated with $14 \%$ higher odds to develop iMN (95\% CI 1.10 to 1.18). The frequency of $i M N$ varied among geographical regions, with the most polluted areas having the highest frequency [30].

All three studies [30-32] addressing glomerular diseases associated with $\mathrm{PM}_{2.5}$ exposure showed that $\mathrm{PM}_{2.5}$ negatively affects the glomeruli. However, the mechanisms by which $\mathrm{PM}_{2.5}$ exposure triggers or exacerbates glomerular diseases remain unknown, requiring more research to elucidate this association. It would be worthwhile to explore whether glomerular diseases presumably linked with a direct toxic insult of $\mathrm{PM}_{2.5}$ exposure on the glomeruli could not be the result of an indirect harmful influence on the glomerular function associated with the progression of tubulointerstitial changes secondary to $\mathrm{PM}_{2.5}$ exposure-linked tubular lesions. The pathophysiological mechanisms of NS development are believed to be associated with autoimmunity that targets the glomerulus. Air pollution and $\mathrm{PM}_{2.5}$ exposure have recently been associated with alterations in autoimmunity, leading to increases in oxidative stress and inflammation, which may trigger autoimmune reactions $[31,77,78]$.

Auto-immune diseases, such as SLE, may be associated with varying $\mathrm{PM}_{2.5}$ exposure. In a cross-sectional study design, Bernatsky et al. [33] investigated whether $\mathrm{PM}_{2.5}$ exposure affected clinical aspects of SLE, listed in the SLE Disease Activity Index version 2000 (SLEDAI-2 K). No clear-cut association between $\mathrm{PM}_{2.5}$ exposure and overall SLEDAI-2 K scores could be demonstrated. The authors stipulated that features of disease activity could have been present early in the 10-day window preceding the assessment but were not present at the time of the hospital visit [33]. However, urinary casts - which reflect renal inflammation - and anti-dsDNA were associated with short-term variations in $\mathrm{PM}_{2.5}$ exposure shortly before the clinical visits ( 24 to $48 \mathrm{~h}$ before). A $10 \mu \mathrm{g} / \mathrm{m}^{3}$ increment in $\mathrm{PM}_{2.5}$ exposure was significantly associated $(\mathrm{p}<0.05)$ with increased odds for the presence of urinary casts $(1.43,95 \% \mathrm{CI} 1.05$ to 1.95$)$ as well as the presence of anti-dsDNA (1.26, 95\% CI 0.96 to 1.65) [33]. $\mathrm{PM}_{2.5}$ exposure could not be associated with clinical disease activity features of SLE. These results suggest that $\mathrm{PM}_{2.5}$ exposure has acute effects on the occurrence of anti-dsDNA and urinary casts; however, as the kinetics of anti-dsDNA and urinary casts are not entirely understood, it is physiologically plausible that these markers vary daily with fluctuating $\mathrm{PM}_{2.5}$ exposure.

\section{Diabetes Mellitus as a Driver of Kidney Function Decline}

Exposure to $\mathrm{PM}_{2.5}$ has been shown to exacerbate preexisting health conditions, such as diabetes, in both humans and animals [79-81]. Diabetes causes damage to the kidneys by narrowing of the afferent and efferent arterioles transporting blood to and from the kidneys $[82,83]$. Therefore, the presence of a pre-existing disease might act as a mediator to adverse kidney outcome(s) following $\mathrm{PM}_{2.5}$ exposure, exacerbating the decline of kidney function.

Diabetes mellitus is a significant risk factor for kidney damage, as blood vessels in the kidney become damaged and high blood pressure will occur. The buildup of water and salts leads to hyperfiltration, causing harm to the nephrons and excess proteinuria [83]. Two studies investigated diabetes mellitus as a mediator of kidney function decline after $\mathrm{PM}_{2.5}$ exposure [34, 35]. A cohort study conducted by Chin and colleagues [35] showed that patients exposed to lower levels of $\mathrm{PM}_{2.5}$ (quartile $1 ; 27.7 \mu \mathrm{g} / \mathrm{m}^{3}$ ) and those exposed to higher levels of $\mathrm{PM}_{2.5}$ (quartile 3; $38.8 \mu \mathrm{g} / \mathrm{m}^{3}$ ) had an annual UACR increase of $3.17 \mathrm{mg} / \mathrm{g}$ and $3.96 \mathrm{mg} / \mathrm{g}$ respectively. A more rapid progression of microalbuminuria $(20-200 \mathrm{mg} / \mathrm{L})$ in patients exposed to higher levels of $\mathrm{PM}_{2.5}$ was observed [35], which may 
be explained by the known effects of $\mathrm{PM}_{2.5}$ on increased insulin resistance [84]. Additionally, Bowe et al. [34] indicated diabetes as a mediator in the association of $\mathrm{PM}_{2.5}$ exposure with kidney disease outcomes in an prospective cohort study, where a $10 \mu \mathrm{g} / \mathrm{m}^{3}$ increment in $\mathrm{PM}_{2.5}$ exposure was associated with increased odds of diabetes $(\mathrm{OR}=1.18,95 \% \mathrm{CI} 1.06$ to 1.32$)$, and also with on average a 1.2-fold increased risk of kidney disease outcomes. However, the proportions of association between $\mathrm{PM}_{2.5}$ exposure and kidney disease outcomes mediated by having diabetes varied: $4.7 \%$ (95\% CI 4.3 to $5.7 \%$ ) for incident eGFR $<60 \mathrm{~mL} / \mathrm{min} / 1.73 \mathrm{~m}^{2}, 4.8 \%$ (95\% CI 4.2 to $5.8 \%$ ) for incident CKD, 5.8\% (95\% CI 5.0 to $7.0 \%$ ) for $\geq 30 \%$ decline in eGFR, and $17.0 \%$ (95\% CI 13.1 to $20.4 \%$ ) for ESRD or $\geq 50 \%$ decline in eGFR [34]. The study showed that only a small proportion $(<6 \%)$ of the association between $\mathrm{PM}_{2.5}$ exposure and the risk of kidney disease outcomes is mediated by diabetes, except for ESRD. The mediation effect of diabetes is much higher for ESRD, likely due to the rapid progression of CKD to ESRD because of diabetes, which may reflect from the relative strength of the association between diabetes and ESRD in comparison to other investigated kidney diseases. However, it is of note that the study conducted by Bowe et al. [34] may not be generalizable to the general population as the cohort only included United States war veterans with a mean age of 62.5 years. Lastly, Feng Y. et al. [55] indicated that when diabetes was the primary cause of kidney failure ( $\mathrm{aHR}=1.25,95 \% \mathrm{CI} 1.13$ to 1.38 ), patients were more vulnerable to high $\mathrm{PM}_{2.5}$ exposure levels with an increased mortality risk.

The occurrence of a pre-existing driver such as diabetes mellitus might exacerbate the effects that $\mathrm{PM}_{2.5}$ exposure exerts on the kidneys and its functioning. The sparse studies indicated that diabetes mellitus might act as a mediator between kidney disease outcomes (e.g., CKD, ESRD) and $\mathrm{PM}_{2.5}$ exposure.

\section{Chronic Kidney Disease}

Diabetes is a significant cause of CKD [85], due to a gradual loss of kidney function over a period of months to years. The development and progression of CKD is associated with an increasing all-cause mortality [86]. The CKD-linked disability-adjusted life-years (DALYs) attributable to $\mathrm{PM}_{2.5}$ globally in 2016 have been estimated at 11.4 million years [4]. There is no consensus yet about the adverse effects of $\mathrm{PM}_{2.5}$ on CKD development and progression. Of all included studies, 17 studies focused on the effects of $\mathrm{PM}_{2.5}$ exposure on CKD [22, 27, 36-49, 51].

Cross-sectional studies conducted by Wang et al. [41] and Yang et al. [42] demonstrated the lack of significant associations between $\mathrm{PM}_{2.5}$ exposure and lower eGFR as an indication of CKD development $(\beta=0.10,95 \%$
CI $-0.30-0.49$ [41] and $\beta=-0.09,95 \%$ CI -0.25 to 0.07 [42], respectively) as well as increased CKD prevalence (OR $=0.99,95 \%$ CI 0.91 to 1.08 [41] and $\mathrm{OR}=1.03,95 \%$ CI 0.97 to 1.09 [42], respectively). However, Wang et al. [41] stipulated that not all crucial confounders were estimated and taken into account in the statistical model(s), which might also be a limitation in the study conducted by Yang and colleagues [42]. Another cross-sectional study, investigating an elderly population ( $\geq 65$ years of age) with stage III to V of CKD, could not show any associations between eGFR as a measure for CKD development or progression and a $4.1 \mu \mathrm{g} / \mathrm{m}^{3} \mathrm{IQR}$ increment of $\mathrm{PM}_{2.5}$ exposure [38]. Of all subjects, $62.8 \%$ had hypertension and $17.5 \%$ had diabetes at the moment of inclusion in the study. Persons were categorized as having low $(68.3 \%)$, moderate $(20.2 \%)$, high $(7.2 \%)$, or very high risk (4.3\%) of CKD progression. For the total population $(\mathrm{n}=8,497)$, the percental changes of eGFR and eGFR $<60 \mathrm{~mL} / \mathrm{min} / 1.73 \mathrm{~m}^{2}$ were 0.24 (95\% CI -0.19 to 0.67 ) and 0.54 (95\% CI -0.21 to 1.26$)$, respectively [38]. In the cohort study by Feng Y.M. et al. [25], focusing on white Europeans $(\mathrm{n}=820$ at the baseline participation and $\mathrm{n}=$ 653 at follow-up) with an average \pm SD age of $51.1 \pm 15.6$ years, the authors observed that changes in CKD stage(s) $\left(\mathrm{OR}_{\text {baseline }}=-0.09,95 \% \mathrm{CI}-0.42\right.$ to $0.24 ; \mathrm{OR}_{\text {follow-up }}=$ $0.04,95 \% \mathrm{CI}-0.29$ to 0.38 ; and $\mathrm{OR}_{\text {combination }}=-0.01,95 \%$ $\mathrm{CI}-0.29$ to 0.26 ) were unrelated to $\mathrm{PM}_{2.5}$ exposure ( $\mathrm{p} \geq$ 0.59 ) when considering only the baseline, only the followup, or a combination of participation.

The cross-sectional study by Chen et al. [38] also evaluated $\mathrm{PM}_{2.5}$ absorbance, which characterizes local soot emissions. For an IQR increment of $\mathrm{PM}_{2.5}$ absorbance of $0.4 \times 10^{-5} / \mathrm{m}$ a significant association was observed with a lower eGFR $(-1.07 \%$ change, $95 \%$ CI $-1.57 \%$ to $-0.54 \%)$, higher $\mathrm{CKD}$ prevalence $(\mathrm{OR}=1.126,95 \% \mathrm{CI} 1.057$ to 1.199$)$, and $\mathrm{CKD}$ progression $(\mathrm{OR}=1.114,95 \% \mathrm{CI}$ 1.051 to 1.181 ) [38]. These results indicate that emission sources, such as from industrial or residential activities, can contribute to airborne PM and locally change the air pollution composition [38, 87].

Ghazi et al. [44] investigated CKD prevalence on adult patients $(\mathrm{n}=113,725)$, where for each $1 \mu \mathrm{g} / \mathrm{m}^{3}$ increase in $\mathrm{PM}_{2.5}$, no association could be demonstrated with CKD prevalence when CKD was defined as having an eGFR $<60$ $\mathrm{mL} / \mathrm{min} / 1.73 \mathrm{~m}^{2}$; however, when CKD was defined as having an eGFR $<45 \mathrm{~mL} / \mathrm{min} / 1.73 \mathrm{~m}^{2}$, the highest quartile (Q4 $\left.\geq 10.7 \mu \mathrm{g} / \mathrm{m}^{3}\right)$ of $\mathrm{PM}_{2.5}$ was associated with greater odds of CKD (OR $=1.18,95 \%$ CI 1.05 to 1.33 ) compared to the lowest quartile $\left(\mathrm{Q} 1<9.5 \mu \mathrm{g} / \mathrm{m}^{3}\right)$. Additionally, each $1 \mu \mathrm{g} /$ $\mathrm{m}^{3}$ increase in $\mathrm{PM}_{2.5}$ concentration could be associated with 7\% greater odds of CKD (95\% CI 1.03 to 1.11). At baseline, $35 \%, 11 \%$, and $9 \%$ of patients had hypertension, diabetes, and/or cardiovascular disease(s), respectively. 
Li G. et al. [48] demonstrated that with each increase of $10 \mu \mathrm{g} / \mathrm{m}^{3} \mathrm{PM}_{2.5}$, a positive association $(\mathrm{p}<0.001)$ could be observed with CKD prevalence (OR $=1.28,95 \%$ CI 1.22 to 1.35) in an adult Chinese population. In this nation-wide cross-sectional study $(\mathrm{n}=47,086)$, a $10 \mu \mathrm{g} /$ $\mathrm{m}^{3}$ increment in $\mathrm{PM}_{2.5}$ was shown to be significantly associated with increased odds for CKD (OR $=1.24$, 95\% CI 1.14 to 1.35 ) at 1- to 4-year moving averages of $\mathrm{PM}_{2.5}$ exposure $(p<0.001)$. Furthermore, stronger increased odds for CKD was demonstrated in rural areas $(\mathrm{OR}=$ $1.51,95 \%$ CI 1.29 to 1.78 ) compared to urban areas (OR $=0.92,95 \%$ CI 0.79 to 1.07$)$ per increase of $10 \mu \mathrm{g} / \mathrm{m}^{3}$ $\mathrm{PM}_{2.5}$ at 2-year moving average $\left(\mathrm{p}_{\text {interaction }}<0.001\right)$ [45]. In the Veterans Affair Normative Aging cohort study by Gao et al. [27], for each $4.09 \mu \mathrm{g} / \mathrm{m}^{3}$ increment in shortterm (28-day) $\mathrm{PM}_{2.5}$ concentration, an increased odds for CKD (OR $=1.1399,95 \%$ CI -0.0099 to 0.2718 ) was observed, albeit non-significant ( $p>0.05)$. Kuźma et al. [49] performed a retrospective cross-sectional study and showed that with each $15.9 \mu \mathrm{g} / \mathrm{m}^{3}$ increment in annual $\mathrm{PM}_{2.5}$ exposure, the odds of CKD significantly increased $(\mathrm{OR}=1.07,95 \% \mathrm{CI} 1.01$ to $1.15 ; \mathrm{p}=0.037)$. Additionally, in a population of 2,482,737 users of the Veterans Affairs Healthcare System, with median of 8.52 years of follow-up, Bowe et al. [51] observed an increased risk of incident CKD (HR $=1.27,95 \%$ CI 1.17 to 1.38 ) for a $10 \mu \mathrm{g} / \mathrm{m}^{3}$ increment in annual average $\mathrm{PM}_{2.5}$ exposure, with an elevated risk at $\mathrm{PM}_{2.5}$ concentrations $>9.2 \mu \mathrm{g} /$ $\mathrm{m}^{3}$ ( $\mathrm{p} \leq 0.05$ ). Of the overall cohort, $67.26 \%, 27.80 \%$, and $29.86 \%$ of persons had a diagnosis of hypertension, diabetes, and/or cardiovascular disease(s), respectively. In a prospective follow-up of 10 years, Blum et al. [22] reached similar conclusions, in that the annual average of $\mathrm{PM}_{2.5}$ exposure in four counties (range: $9.4-15.3 \mu \mathrm{g} /$ $\mathrm{m}^{3}$ ) was significantly associated with an increased risk of CKD $(\mathrm{HR}=1.05,95 \%$ CI 1.01 to $1.10 ; \mathrm{p}<0.05)$. Here, $16 \%, 46 \%$, and $19 \%$ participants exposed to lower or equal to the site-specific median (range: $9.4-15.3 \mu \mathrm{g} /$ $\mathrm{m}^{3}$ ) had diabetes, hypertension, and composite cardiovascular disease, respectively. Comorbidity was similar for participants exposed to a higher site-specific median ( $17 \%$ for diabetes, $49 \%$ for hypertension, and $20 \%$ for composite cardiovascular disease). Furthermore, a population-based longitudinal cohort study conducted in Taiwan [37] showed that a higher level of $\mathrm{PM}_{2.5}$ exposure was associated with a higher risk of developing CKD. At the baseline of the study, $16.0 \%$ and $5.0 \%$ of participants had a diagnosis of hypertension or diabetes, respectively [88]. Relative to the participants exposed to low $\mathrm{PM}_{2.5}$ exposure levels $\left(5.8-21.1 \mu \mathrm{g} / \mathrm{m}^{3}\right)$, those exposed to higher $\mathrm{PM}_{2.5}$ levels $\left(>25.5 \mu \mathrm{g} / \mathrm{m}^{3}\right)$ had a significantly increased risk of developing CKD (HR $=1.15,95 \% \mathrm{CI}$ 1.05 to $1.26 ; \mathrm{p}<0.05$ ) [37]. For a $10 \mu \mathrm{g} / \mathrm{m}^{3}$ increment of
$\mathrm{PM}_{2.5}$ exposure, Chan et al. [37] reported a significant risk of CKD incidence $(\mathrm{HR}=1.06,95 \% \mathrm{CI} 1.02$ to $1.10 ; \mathrm{p}$ $<0.05)$. In another longitudinal cohort study also evaluating the general Taiwanese population $(\mathrm{n}=104,092)$ with a follow-up $\geq 3$ years, each increment of $10 \mu \mathrm{g} / \mathrm{m}^{3} \mathrm{PM}_{2.5}$ could be significantly associated with a 2.66 -fold $(95 \% \mathrm{CI}$ 2.43 to 2.90$)$ increased risk of developing CKD $(\mathrm{p}<0.001)$ [47]. Ghazi et al. [44] also investigated CKD incidence in the adult patient population with no CKD at baseline $(\mathrm{n}=20,289)$ and observed that each $1 \mu \mathrm{g} / \mathrm{m}^{3}$ increase in baseline annual average $\mathrm{PM}_{2.5}$ was associated with an increased risk of CKD (HR $=1.78,95 \%$ CI 1.65 to 1.89 ; $\mathrm{p}<0.05)$. Increasing risk was demonstrated for increasing quartiles of baseline $\mathrm{PM}_{2.5}$ exposure, with an $\mathrm{HR}$ of $1.72,2.15$, and 2.49 for the second (Q2 $\left.9.5-10.1 \mu \mathrm{g} / \mathrm{m}^{3}\right)$, third (Q3 10.1 to $\left.10.7 \mu \mathrm{g} / \mathrm{m}^{3}\right)$ and fourth $(\mathrm{Q} 4 \geq 10.7 \mu \mathrm{g} /$ $\mathrm{m}^{3}$ ) quartiles of $\mathrm{PM}_{2.5}$ exposure compared to quartile one $\left(\mathrm{Q} 1<9.5 \mu \mathrm{g} /{ }^{3}\right)(\mathrm{p}<0.05)$.

A third nation-wide Taiwanese study by Lin S.Y. et al. [39] reported that exposure levels of $\mathrm{PM}_{2.5}$ above $28.3 \mu \mathrm{g} /$ $\mathrm{m}^{3}$ (quartile 1) were associated with increased hazard ratios of CKD risk $(\mathrm{p}<0.001)$. They showed an increased risk of CKD incidence for a $1 \mu \mathrm{g} / \mathrm{m}^{3}$ increment in $\mathrm{PM}_{2.5}$ exposure (HR $=1.03,95 \%$ CI 1.02 to 1.03$)$ [39]. It is of note that $29.1 \%, 10.1 \%$, and $14.1 \%$ of participants had hypertension, diabetes, and coronary artery disease at the time of measurements. In an ecological study by BraggGresham et al. [36] addressing the elderly population (age $\geq 65$ years), $28.6 \%$ and $73.2 \%$ of the participants in the low $\left(\leq 12.2 \mu \mathrm{g} / \mathrm{m}^{3}\right) \mathrm{PM}_{2.5}$ exposure group had a diagnosis of diabetes and hypertension respectively, $32.2 \%$ and $77.4 \%$ were diagnosed with diabetes and hypertension respectively in the high $\mathrm{PM}_{2.5}$ exposure group (>12.2 $\mu \mathrm{g} /$ $\left.\mathrm{m}^{3}\right)$. For all participants in their Medicare population cohort ( $\mathrm{n}=1,164,057)$, the study showed a prevalence ratio of 1.03 (95\% CI 1.02 to 1.05 ) of diagnosed CKD in association with a $4 \mu \mathrm{g} / \mathrm{m}^{3}$ increment of $\mathrm{PM}_{2.5}$ exposure. However, it is of note that this positive association between $\mathrm{PM}_{2.5}$ exposure and diagnosed CKD was shown in an elderly population; hence, these results may not be generalizable for younger (sub)populations.

Ran et al. [40] investigated the mortality risk of ambient $\mathrm{PM}_{2.5}$ exposure on cause-specific mortality in CKD patients in a prospective study design, where $67.0 \%$ and $34.9 \%$ had self-reported diabetes and hypertension, respectively. They reported an adjusted HR of 1.13 (95\% CI 0.98 to 1.30) on all-cause mortality. Furthermore, a $4.0 \mu \mathrm{g} / \mathrm{m}^{3} \mathrm{IQR}$ increment of $\mathrm{PM}_{2.5}$ was associated with mortality from CKD progression ( $\mathrm{HR}=1.17,95 \%$ CI 0.89 to 1.53) [40]. In a retrospective cohort study by Jung et al. [43], CKD patients were followed up to evaluate mortality risk after $\mathrm{PM}_{2.5}$ exposure. Of these CKD patients, $21 \%$ and $36 \%$ reportedly had diabetes and hypertension, 
respectively. The authors observed that CKD patients who survived were exposed to lower levels of $\mathrm{PM}_{2.5}$ exposure than the CKD patients who passed away during the study period $(\mathrm{p}<0.001)$. For each $2.55 \mu \mathrm{g} / \mathrm{m}^{3} \mathrm{IQR}$ increment in $\mathrm{PM}_{2.5}$ concentration, a significantly increased risk of mortality was observed $(\mathrm{HR}=1.17,95 \% \mathrm{CI} 1.07$ to 1.29; $\mathrm{p}=0.019$ ). Therefore, $\mathrm{PM}_{2.5}$ exposure may not only play a crucial role in the worsening of CKD, but may also contribute to circulatory damage and be involved in a synergistic effect between hypertension and $\mathrm{PM}_{2.5}$ exposure, which may accelerate CKD progression into renal failure $[40,89]$.

In a longitudinal cohort study by Bo and colleagues [46], 163,197 participants were followed up for an average of 5.1 years (range 1.0 to 15.9 years). Of participants, $12.7 \%$ and $3.3 \%$ had hypertension and diabetes, respectively. Bo et al. [46] stipulated that for each $5 \mu \mathrm{g} / \mathrm{m}^{3}$ decrease in $\mathrm{PM}_{2.5}$ levels, positive associations were found for incident CKD ( $\mathrm{HR}=0.75,95 \% \mathrm{CI} 0.73$ to 0.78 ). They concluded that a lower risk of CKD development could be associated with chronic $\mathrm{PM}_{2.5}$ exposure improvement. This is the first study to suggest that reducing air pollution may be an effective strategy for the prevention of CKD.

It is important to note that out of seventeen studies, only the studies by Chen et al. [38] and Feng Y.M. et al. [25] addressed stages of CKD that were included in their analysis; all other studies did not. Ran et al. [40] suggested that CKD patients enrolled in their study could be in the moderate to high stages, as symptoms were severe enough to be hospitalized. Furthermore, not every study addressed significant drivers of the development and progression of CKD, such as hypertension [22, 36-40, $43-49,51]$, diabetes [22, 36-40, 43-48, 51], and cardiovascular disease $[22,39,44,45,47,48,51]$.

Of the seventeen studies [22, 27, 36-49, 51] evaluating the association between $\mathrm{PM}_{2.5}$ exposure and CKD, five could not show any associations [25, 38, 41, 42, 44]; however, the evidence showing an effect of ambient $\mathrm{PM}_{2.5}$ exposure on CKD development, incidence, prevalence, and mortality is rising. As the global burden of CKD attributable to $\mathrm{PM}_{2.5}$ exposure is significant, efforts to improve ambient air quality are necessary to mitigate this burden $[4,51]$.

\section{End-Stage Renal Disease and Kidney Failure}

CKD may gradually worsen into an advanced stage, termed end-stage renal disease (ESRD), requiring invasive treatments, such as dialysis or kidney transplantation, to maintain quality of life. Even though the prevalence and incidence of ESRD rise globally [50], the association with $\mathrm{PM}_{2.5}$ exposure remains to be elucidated $[50,51]$. Of the included studies, the effects of $\mathrm{PM}_{2.5}$ on the (risk of) development of ESRD was addressed in 3 studies [39, 50, 51].

Relative to low $\mathrm{PM}_{2.5}$ exposure levels $(\mathrm{Q} 1 \leq 11.71$ $28.69 \mu \mathrm{g} / \mathrm{m}^{3}$ ), Wu et al. [50] found for patients exposed to higher exposure levels (Q4 $39.96-46.63 \mu \mathrm{g} / \mathrm{m}^{3}$ ), an increased risk of developing ESRD ( $\mathrm{HR}=1.15,95 \% \mathrm{CI}$ 1.01 to $1.30 ; \mathrm{p}<0.05)$ and also a higher cumulative incidence of ESRD, compared to patients exposed to lower $\mathrm{PM}_{2.5}$ levels $\left(<39.96 \mu \mathrm{g} / \mathrm{m}^{3}\right)$, in a prospective study design. An IQR increment of $11.31 \mu \mathrm{g} / \mathrm{m}^{3}$ in $\mathrm{PM}_{2.5}$ exposure was associated with a $8 \%$ elevated risk of developing ESRD (95\% CI 1.00 to 1.15) [50]. Bowe et al. [51] reported that for a $10 \mu \mathrm{g} / \mathrm{m}^{3}$ increment in $\mathrm{PM}_{2.5}$ the risk of developing ESRD was 1.31 (95\% CI 1.21 to 1.43) Per 100,000 person-years, the incident rate of ESRD was 44.36 (95\% CI 44.27 to 44.45) with higher incidence rates for increasing $\mathrm{PM}_{2.5}$ levels $(\mathrm{p} \leq 0.05)$. Another prospective nationwide cohort study reported similar results, in that ESRD risk increased for an increment of $1 \mu \mathrm{g} / \mathrm{m}^{3}$ daily average $\mathrm{PM}_{2.5}$ exposure $(\mathrm{aHR}=1.02,95 \% \mathrm{CI} 1.01$ to $1.03 ; \mathrm{p} \leq$ 0.01) [39]. The risk of developing ESRD was more elevated for higher levels of $\mathrm{PM}_{2.5}$ exposure $\left(>34.0 \mu \mathrm{g} / \mathrm{m}^{3}\right)$, relative to participants exposed to lower $\mathrm{PM}_{2.5}$ concentrations $\left(<28.3 \mu \mathrm{g} / \mathrm{m}^{3}\right)$ [39].

When components of the kidneys, such as the glomeruli, the tubules, or the tubule-interstitium are damaged, CKD may develop and rapidly progress into ESRD [90]. The hypothesis emerging from recent studies that the development of CKD may be causally linked to air pollution, and more specifically to $\mathrm{PM}_{2.5}$ exposure, requires more research to unravel the mechanisms of $\mathrm{PM}_{2.5}$ involvement in the development of CKD and its rapid progression and/or exacerbation into ESRD [4, 39].

Progression of CKD could also lead to kidney failure, the progressive loss of kidney function. It is believed that the prevalence of kidney failure and the need for replacement therapy will double in the next years, leading to substantial socioeconomic costs [52, 53]. Six studies investigated the effects of $\mathrm{PM}_{2.5}$ exposure on the development, progression, and visits to the emergency room because of mortality from renal failure [32, 40, 52-55].

In a time-series study by Bi et al. [54], positive associations could be observed between short-term exposure to $\mathrm{PM}_{2.5}$ (8-day) and emergency room visits due to acute renal failure [relative risk $(\mathrm{RR})=1.026,95 \%$ CI 0.997 to 1.057 ] per IQR $\left(8.99 \mu \mathrm{g} / \mathrm{m}^{3}\right)$ increase of $\mathrm{PM}_{2.5}$ exposure. Overall, results showed that exposure to $\mathrm{PM}_{2.5}$ for a longer period was associated with a higher risk of kidney disease outcomes. Furthermore, another time-series conducted by $\mathrm{Gu}$ et al. [32] investigated the number of hospital admissions attributed to kidney failure. Not only was kidney failure shown to be significantly positively associated with same-day $\mathrm{PM}_{2.5}$ exposure, but a $10 \mu \mathrm{g} / \mathrm{m}^{3}$ 
increment of $\mathrm{PM}_{2.5}$ exposure was associated ( $<<0.001$ ) with a $0.32 \%$ change in hospital admissions ( $95 \%$ CI 0.19 to 0.45 ) attributable to kidney failure.

In a cohort study by Feng Y. et al. [55], the authors showed that for older patients ( $\geq 65$ years) on their firsttime maintenance dialysis, a $10 \mu \mathrm{g} / \mathrm{m}^{3}$ increase in $\mathrm{PM}_{2.5}$ concentration could be associated with a 1.16-fold (95\% CI 1.08 to 1.25 ) increased risk of mortality. Furthermore, these associations were stronger at higher levels $(>12 \mu \mathrm{g} /$ $\left.\mathrm{m}^{3}\right)$ of $\mathrm{PM}_{2.5}(\mathrm{aHR}=1.19,95 \%$ CI 1.08 to 1.32$)$, but were still significantly associated at lower levels $\left(\leq 12 \mu \mathrm{g} / \mathrm{m}^{3}\right)$ of $\mathrm{PM}_{2.5}$ with mortality risk $(\mathrm{aHR}=1.04,95 \%$ CI 1.00 -1.07 ).

Ran et al. [40] showed that a $4.0 \mu \mathrm{g} / \mathrm{m}^{3}$ IQR increment of $\mathrm{PM}_{2.5}$ exposure was associated with an increased risk of renal failure mortality in CKD patients $(\mathrm{HR}=1.18$, 95\% CI 0.91 to 1.52 ) and CKD patients with existing hypertension ( $\mathrm{HR}=1.42,95 \% \mathrm{CI} 1.05$ to 1.93$)$. Moreover, CKD patients with hypertension had a significantly higher risk of renal failure mortality $(\mathrm{HR}=1.42,95 \% \mathrm{CI}$ 1.05 to 1.93; $\mathrm{p}<0.05)$. A retrospective study by Ran et al. [52] investigated whether the risk of kidney failure mortality differed between a cohort of the general elderly population ( $\geq 65$ years of age; $n=61,447$ ) and patients diagnosed with CKD. They showed that a $3.22 \mu \mathrm{g} / \mathrm{m}^{3}$ IQR increment of $\mathrm{PM}_{2.5}$ exposure was associated with increased mortality risk in both the cohort participants $(\mathrm{HR}=1.23,95 \% \mathrm{CI} 1.06$ to $1.43 ; \mathrm{p}<0.01)$ and the patients diagnosed with CKD (HR $=1.42,95 \%$ CI 1.16 to 1.74; $\mathrm{p} \leq 0.001$ ). The subcategory analysis of renal failure, including the development of all incidence cases of acute kidney injury and CKD, also showed significant associations ( $\mathrm{p} \leq 0.001)$ with $\mathrm{PM}_{2.5}$ exposure [52]. Similar results were obtained by the prospective cohort study by Lin Y.T. and colleagues [53], in that patients with CKD who were exposed to higher $\mathrm{PM}_{2.5}$ levels $\left(>32.08 \mu \mathrm{g} / \mathrm{m}^{3}\right)$ had a significantly increased risk of progression of CKD into kidney failure, requiring replacement therapy (e.g., dialysis) (aHR $=1.42$, 95\% CI 1.12 to $1.80 ; \mathrm{p}<0.001$ ). Moreover, an apparent dose-effect relationship was observed for a $7.8 \mu \mathrm{g} / \mathrm{m}^{3}$ IQR increment in the average 1-year $\mathrm{PM}_{2.5}$ exposure, which was significantly associated with a $19 \%$ greater risk of CKD progression (95\% CI 1.08 to 1.31) [53]. However, no significant association could be shown between $\mathrm{PM}_{2.5}$ exposure and kidney failure requiring replacement therapy; furthermore, kidney failure requiring replacement therapy was significantly mediated by variability in 1-year estimated eGFR [53]. This suggests that nephrotoxic effects of $\mathrm{PM}_{2.5}$ might play a predominant role in CKD progression $[51,53]$.

All conducted studies evaluating the association between $\mathrm{PM}_{2.5}$ exposure and renal failure showed associations; not only development of CKD, ESRD, and renal failure have shown to be associated with $\mathrm{PM}_{2.5}$ exposure, but $\mathrm{PM}_{2.5}$ may also be involved in the progression from CKD to ESRD and eventually, renal failure.

\section{Kidney Transplantation}

Vulnerable subpopulations, such as kidney transplant recipients, experience enhanced susceptibility due to triggering of the immune system by $\mathrm{PM}_{2.5}$, leading to inflammation $[16,56]$. A retrospective cohort study by Pierotti et al. [56] found significant associations between the risk of kidney transplant failure and $\mathrm{PM}_{2.5}$ exposure. An increment of $5 \mu \mathrm{g} / \mathrm{m}^{3} \mathrm{PM}_{2.5}$ was associated with an increased transplant failure risk ( $\mathrm{HR}=1.25,95 \% \mathrm{CI} 1.02$ to 1.53); however, this association lost its significance after adjustment for confounders. The study concluded that there are no adverse effects of $\mathrm{PM}_{2.5}$ exposure on kidney transplant outcomes. However, a retrospective cohort study by Chang et al. [57] showed that higher baseline $\mathrm{PM}_{2.5}$ levels (the annual mean in the year before kidney transplantation), compared to the Q1 $\mathrm{PM}_{2.5}$ levels $\left(1.2\right.$ to $\left.<8.3 \mu \mathrm{g} / \mathrm{m}^{3}\right)$, were not associated with higher odds (aOR $=0.99,95 \%$ CI 0.92 to 1.06$)$ of acute kidney rejection for Q2 $\mathrm{PM}_{2.5}$ levels $\left(8.3\right.$ to $<9.8 \mu \mathrm{g} / \mathrm{m}^{3}$ ), but could be associated with increased odds $(\mathrm{aOR}=1.11$, 95\% CI 1.04 to 1.20) for Q3 $\mathrm{PM}_{2.5}$ levels (9.8 to $<11.9 \mu \mathrm{g} /$ $\left.\mathrm{m}^{3} ; \mathrm{p}<0.001\right)$. Feng $\mathrm{Y}$. and colleagues [59] demonstrated that with each $10 \mu \mathrm{g} / \mathrm{m}^{3}$ increase in $\mathrm{PM}_{2.5}$ concentration, a 1.31 -fold higher odds (95\% CI 1.17 to 1.46 ) of one-year acute rejection was observed. That association was not present when the analysis was restricted to kidney transplant recipients who were exposed to $\mathrm{PM}_{2.5}$ concentrations $\leq 12 \mu \mathrm{g} / \mathrm{m}^{3}(\mathrm{OR}=1.02,95 \%$ CI 0.87 to 1.19). Furthermore, Feng Y. et al. [59] stipulated that each $10 \mu \mathrm{g} / \mathrm{m}^{3}$ increase in $\mathrm{PM}_{2.5}$ was associated with a 1.59 fold (95\% CI 1.46 to 1.73 ) higher odds of delayed graft function after transplantation; this association remained consistent, even when the analysis was restricted to kidney transplant recipients who were exposed to $\leq 12 \mu \mathrm{g} /$ $\mathrm{m}^{3} \mathrm{PM}_{2.5}$ (OR $=1.75,95 \% \mathrm{CI} 1.55$ to 1.98$)$.

Additionally, an increased risk of death-censored graft failure ( $\mathrm{aHR}=1.17,95 \% \mathrm{CI} 1.09$ to 1.25$)$ and all-cause mortality (aHR $=1.21,95 \%$ CI 1.14 to 1.28 ) was shown per $10 \mu \mathrm{g} / \mathrm{m}^{3}$ increase in $\mathrm{PM}_{2.5}$ exposure levels. However, Feng Y. et al. [59] could not show an association between each $10 \mu \mathrm{g} / \mathrm{m}^{3}$ increase in $\mathrm{PM}_{2.5}$ and death-censored graft failure (HR $=1.05,95 \% \mathrm{CI} 0.97$ to 1.15 ), but could associate all-cause mortality $(\mathrm{HR}=1.15,95 \%$ CI $1.07-1.23$; $\mathrm{p}$ $<0.05)$. In a retrospective cohort study, Dehom et al. [58] also showed that a $10 \mu \mathrm{g} / \mathrm{m}^{3}$ increase in $\mathrm{PM}_{2.5}$ exposure levels granted an increased risk of all-cause mortality (HR $=3.45,95 \%$ CI 3.08 to $3.78 ; \mathrm{p}<0.05$ ) in kidney transplant recipients. Furthermore, results indicated that black 
recipients had a higher risk of all-cause mortality ( $\mathrm{HR}=$ $4.09,95 \%$ CI 3.43 to 4.88 ) than non-black recipients.

In short, results indicating an association between $\mathrm{PM}_{2.5}$ exposure and kidney transplant outcome are ambivalent. However, due to the scarce evidence about the mediating effects of pre-existing reduced kidney function on $\mathrm{PM}_{2.5}$ exposure and kidney function outcomes, it is too early to infer on the impact of $\mathrm{PM}_{2.5}$ exposure on kidney transplant survival. Further research is required. The occurrence of a pre-existing reduced kidney function and chronic immunosuppression might exacerbate the effects that $\mathrm{PM}_{2.5}$ exposure exerts on the kidneys and their functioning $[56,59]$.

\section{Limitations of Included Studies}

The studies included in this systematic review hold some general limitations that must be addressed. Outdoor air pollution, such as $\mathrm{PM}_{2.5}$, has been investigated in association with e.g., atherosclerosis, hypertension, and coronary calcification. These conditions are mediators to kidney disease outcomes, which may cause indirect systemic detrimental effects on the kidney. However, although some studies in this review adjusted for these mediators in their statistical models, the effects exerted by $\mathrm{PM}_{2.5}$ on these mediators may aggravate and/or accelerate the kidney outcome investigated. Therefore, it is an interesting scope to investigate the mediation of e.g., hypertension in the $\mathrm{PM}_{2.5}$-kidney association, as has been done by Bowe et al. [34] for diabetes. Another limitation of the included studies is the homogeneity as to the examination of ethnic (sub) populations. Additional research is required on various polluted areas and ethnic (sub)populations to thoroughly investigate the impact of $\mathrm{PM}_{2.5}$ exposure on people's renal health [40] and to extrapolate the findings to the general population as suggested by different authors $[15,23,28$, $29,33-35,37,38,40,52$, 56]. Furthermore, a substantial limitation is the absence of personalized $\mathrm{PM}_{2.5}$ exposure measurements or relying on only residential (regional or national) exposure levels. People do not spend their entire time during the day at the home address; therefore, all locations and the time spent at each location should be considered when determining exposure estimates [22, 30, 31, $37,39,53]$. Even though $\mathrm{PM}_{2.5}$ has a greater specific surface area to facilitate the binding of toxic compounds, the composition of $\mathrm{PM}_{2.5}$ might heavily influence the adverse effects seen following exposure and might explain the vast differences seen between studies [91]. Residual confounding, such as smoking status, may be a limitation for determining the effects of $\mathrm{PM}_{2.5}$ exposure on an individual basis. However, when the studies treat the populations as one group, such as a time-series study, the influence of individual factors is minor. Moreover, the studies addressing the development and/or worsening of CKD did not always include comorbidity, (e.g., hypertension [36-38, 40]), and the stage of disease present at time of the inclusion [22, 36, 37, 39, 40, 51]. Furthermore, no studies investigated the underlying effects and mechanisms of $\mathrm{PM}_{2.5}$ exposure on specific kidney morphology and function or particulate biodistribution within the kidney. It would be interesting to investigate which structural renal components $\mathrm{PM}_{2.5}$ particles reach and potentially adversely affect.

\section{Conclusions and Future Directions}

Epidemiological research assessed within this review revealed that $\mathrm{PM}_{2.5}$ air pollution presents significant public health risks, even at exposure levels below the previous standards set by the WHO [60]. Ran et al. $[40,52]$ stipulated that experimentally designed studies about the direct impact of $\mathrm{PM}_{2.5}$ on the renal system are still very limited $[39,51]$. Causal evidence of the harmful effects of $\mathrm{PM}_{2.5}$ exposure on kidney function is still scarce, and the biological mechanisms of toxic action by which $\mathrm{PM}_{2.5}$ affects the kidneys or exacerbates kidney disease outcomes is not entirely elucidated until this day [34].

$\mathrm{PM}_{2.5}$ is an important, yet not fully recognized risk factor for kidney functioning and kidney disease outcome(s). On the other hand, because of the great variety of the investigated subpopulations, the contradictory findings, and the lack of sufficient studies addressing each subgroup of kidney disease(s), no summarizing consensus view can be reached across studies dealt within this systematic review. We conclude that more clarifying research is warranted to further elucidate the complex findings of $\mathrm{PM}_{2.5}$-linked effects on kidney function and kidney disease(s) to extrapolate the results to the general population and to evaluate the geographical variations in kidney disease(s) in the light of varying $\mathrm{PM}_{2.5}$ exposure levels.

\section{Supplementary Information}

The online version contains supplementary material available at https://doi. org/10.1186/s12940-021-00827-7.

Additional file 1: Supplementary Table 1. Risk of bias analysis performed according to the Newcastle-Ottawa scale. Crosses ( $x$ ) indicate the allocation of a point in the scale; The minus sign (-) indicates the failure to accommodate the subject(s) discussed. Ascertainment of exposure checks the derivation of the exposure measurements $(x)$ and the demonstration that the outcome of interest was not present at the start of the study $(x)$. Comparability encompasses the presence of the main confounder age $(x)$ and any additional confounder(s) $(x)$ respectively. Articles were considered to have a high risk of bias below 4 points, a medium risk of bias below 6 points, and a low risk of bias above or equal to 6 points.

\section{Acknowledgements}

Not applicable. 


\section{Authors' contributions}

$L R, K V B$, and $H B$ have contributed to the definition of the scope of the review. $L R$ and KVB identified studies, summarized all eligible articles, synthesized the findings, and drafted the manuscript. TN, MP, KVB, KDV, HB, and HAR provided critical comments. Each author contributed to important intellectual content during manuscript drafting or revision. All authors read and approved the final manuscript.

\section{Funding}

The authors acknowledge funding from the Special Research Fund (BOF) from Hasselt University granted to LR (BOF20DOC15) and the Flemish Scientific Research Foundation (FWO) funding granted to KVB (G059219N). BOF and FWO had no role in the design, conduct, and preparation of the manuscript.

\section{Availability of data and materials}

Data sharing is not applicable to this article as no datasets were generated or analysed during this systematic review.

\section{Declarations}

\section{Ethics approval and consent to participate}

Not applicable.

\section{Consent for publication}

Not applicable.

\section{Competing interests}

The authors declare that they have no competing interests.

\section{Author details}

${ }^{1}$ Centre for Environmental Sciences, Hasselt University, Agoralaan Gebouw D, B-3590 Diepenbeek, Belgium. ${ }^{2}$ Nephrology and Kidney Transplantation, University Hospital Leuven, Leuven, Belgium. ${ }^{3}$ Department of Microbiology, Immunology, and Transplantation, Leuven University, Leuven, Belgium. ${ }^{4}$ Louvain Centre for Toxicology and Applied Pharmacology, Université catholique de Louvain, Brussels, Belgium. ${ }^{5}$ Department of Public Health and Primary Care, Environment and Health Unit, Leuven University, Leuven, Belgium.

Received: 30 June 2021 Accepted: 27 December 2021

Published online: 08 February 2022

\section{References}

1. Xu X, Nie S, Ding H, Hou FF. Environmental pollution and kidney diseases. Nat Rev Nephrol. 2018;14(5):313.

2. Arnold R, Issar T, Krishnan AV, Pussell BA. Neurological complications in chronic kidney disease. JRSM Cardiovasc Disease. 2016;5:2048004016677687.

3. Wang XH, Mitch WE. Mechanisms of muscle wasting in chronic kidney disease. Nat Rev Nephrol. 2014;10(9):504.

4. Bowe B, Xie Y, Li T, Yan Y, Xian H, Al-Aly Z. Estimates of the 2016 global burden of kidney disease attributable to ambient fine particulate matter air pollution. BMJ Open. 2019;9(5):e022450.

5. LV J-C, Zhang L-X. Prevalence and disease burden of chronic kidney disease. Renal Fibrosis: Mechanisms and Therapies. 2019:3-15.

6. System USRD. 2020 USRDS Annual Data Report: Epidemiology of kidney disease in the United States. National Institutes of Health, National Institute of Diabetes and Digestive and Kidney Diseases, Bethesda, MD, 2020.

7. Loomis D, Grosse Y, Lauby-Secretan B, El Ghissassi F, Bouvard V, Benbrahim-Tallaa $L$, et al. The carcinogenicity of outdoor air pollution. Lancet Oncol. 2013;14(13):1262

8. Elliott CT, Copes R. Burden of mortality due to ambient fine particulate air pollution (PM 2.5) in interior and Northern BC. Can J Public Health. 2011;102(5):390-3.

9. Shaddick G, Thomas M, Mudu P, Ruggeri G, Gumy S. Half the world's population are exposed to increasing air pollution. NPJ Climate Atmospheric Science. 2020;3(1):1-5.

10. Organization WH. WHO global air quality guidelines: particulate matter (PM2. 5 and PM10), ozone, nitrogen dioxide, sulfur dioxide and carbon monoxide: executive summary. 2021.
11. Nemmar A, Hoet PM, Vanquickenborne B, Dinsdale D, Thomeer M, Hoylaerts $M$, et al. Passage of inhaled particles into the blood circulation in humans. Circulation. 2002;105(4):411-4

12. Bové $H$, Bongaerts E, Slenders E, Bijnens EM, Saenen ND, Gyselaers W, et al. Ambient black carbon particles reach the fetal side of human placenta. Nature Communications. 2019;10(1):1-7.

13. Maher BA, Ahmed IA, Karloukovski V, MacLaren DA, Foulds PG, Allsop D, et al. Magnetite pollution nanoparticles in the human brain. Proc Natl Acad Sci. 2016;113(39):10797-801.

14. Saenen ND, Bové H, Steuwe C, Roeffaers MB, Provost EB, Lefebvre W, et al. Children's urinary environmental carbon load. A novel marker reflecting residential ambient air pollution exposure? Am J Respir Crit Care Med. 2017;196(7):873-81.

15. Zhao Y, Cai J, Zhu X, van Donkelaar A, Martin RV, Hua J, et al. Fine particulate matter exposure and renal function: A population-based study among pregnant women in China. Environ Int. 2020;141:105805.

16. Finn WF. Renal response to environmental toxics. Environ Health perspectives. 1977;20:15-26.

17. Moher D, Weeks L, Ocampo M, Seely D, Sampson M, Altman DG, et al. Describing reporting guidelines for health research: a systematic review. J Clin Epidemiol. 2011;64(7):718-42.

18. Becherucci F, Roperto RM, Materassi M, Romagnani P. Chronic kidney disease in children. Clin Kidney J. 2016;9(4):583-91.

19. Čukuranović R, Vlajković S. Age related anatomical and functional characteristics of human kidney. Organ. 2005;7:14.

20. Wells G, Shea B, O'connell D, Peterson J, Welch V, Losos M, et al. The Newcastle-Ottawa Scale (NOS) for Assessing the Quality of Nonrandomized Studies in Meta-Analyses. Ottawa Health Research Institute: Ottawa, Ontario, 2010. 2015.

21. Fang J, Tang S, Zhou J, Zhou J, Cui L, Kong F, et al. Associations between Personal PM2. 5 Elemental Constituents and Decline of Kidney Function in Older Individuals: the China BAPE Study. Environ Sci Technol. 2020;54(20):13167-74.

22. Blum MF, Surapaneni A, Stewart JD, Liao D, Yanosky JD, Whitsel EA, et al. Particulate Matter and Albuminuria, Glomerular Filtration Rate, and Incident CKD. Clin J Am Soc Nephrol. 2020;15(3):311-9.

23. Mehta AJ, Zanobetti A, Bind MA, Kloog I, Koutrakis P, Sparrow D, et al. Long-Term Exposure to Ambient Fine Particulate Matter and Renal Function in Older Men: The Veterans Administration Normative Aging Study. Environ Health Perspect. 2016;124(9):1353-60.

24. Li A, Mei Y, Zhao M, Xu J, Li R, Zhao J, et al. Associations between air pollutant exposure and renal function: A prospective study of older adults without chronic kidney disease. Environ Pollut. 2021;277:116750.

25. Feng Y, Thijs L, Zhang Z-Y, Bijnens EM, Yang W-Y, Wei F-F, et al. Glomerular Function in Relation to Fine Airborne Particulate Matter in a Representative Population Sample. 2021.

26. Li Q, Wang Y-Y, Guo Y, Zhou H, Wang Q-M, Shen H-P, et al. Association between airborne particulate matter and renal function: An analysis of 2.5 million young adults. Environ Int. 2021;147:106348.

27. Gao X, Koutrakis P, Coull B, Lin X, Vokonas P, Schwartz J, et al. Short-term exposure to PM2. 5 components and renal health: Findings from the Veterans Affairs Normative Aging Study. J Hazard Mater. 2021;420:126557.

28. Chuang KJ, Pan CH, Su CL, Lai CH, Lin WY, Ma CM, et al. Urinary neutrophil gelatinase-associated lipocalin is associated with heavy metal exposure in welding workers. Sci Rep. 2015;5:18048.

29. Weaver AM, Wang Y, Wellenius GA, Young B, Boyle LD, Hickson DA, et al. Long-term exposure to ambient air pollution and renal function in African Americans: the Jackson Heart Study. J Expo Sci Environ Epidemiol. 2019;29(4):548

30. Xu X, Wang G, Chen N, Lu T, Nie S, Xu G, et al. Long-Term Exposure to Air Pollution and Increased Risk of Membranous Nephropathy in China. J Am Soc Nephrol. 2016;27(12):3739-46.

31. Lin S-Y, Hsu W-H, Lin C-L, Lin C-C, Lin C-H, Wang I, et al. Association of exposure to fine-particulate air pollution and acidic gases with incidence of nephrotic syndrome. Int J Environ Res Public Health. 2018;15(12):2860.

32. Gu J, Shi Y, Zhu Y, Chen N, Wang H, Zhang Z, et al. Ambient air pollution and cause-specific risk of hospital admission in China: A nationwide timeseries study. PLoS Med. 2020;17(8):e1003188.

33. Bernatsky S, Fournier M, Pineau CA, Clarke AE, Vinet E, Smargiassi A. Associations between ambient fine particulate levels and disease activity in patients with systemic lupus erythematosus (SLE). Environ Health Perspect. 2011;119(1):45-9. 
34. Bowe B, Xie Y, Yan Y, Xian H, Al-Aly Z. Diabetes Minimally Mediated the Association Between PM(2.5) Air Pollution and Kidney Outcomes. Sci Rep. 2020;10(1):4586

35. Chin WS, Chang YK, Huang LF, Tsui HC, Hsu CC, Guo YL. Effects of long-term exposure to $\mathrm{CO}$ and $\mathrm{PM}(2.5)$ on microalbuminuria in type 2 diabetes. Int J Hyg Environ Health. 2018;221(4):602-8.

36. Bragg-Gresham J, Morgenstern H, McClellan W, Saydah S, Pavkov M, Williams $D$, et al. County-level air quality and the prevalence of diagnosed chronic kidney disease in the US Medicare population. PLoS ONE. 2018;13(7).

37. Chan TC, Zhang Z, Lin BC, Lin C, Deng HB, Chuang YC, et al. Long-term exposure to ambient fine particulate matter and chronic kidney disease: A cohort study. Environ Health Perspectives. 2018;126(10).

38. Chen SY, Chu DC, Lee JH, Yang YR, Chan CC. Traffic-related air pollution associated with chronic kidney disease among elderly residents in Taipei City. Environ Pollut. 2018;234:838-45.

39. Lin SY, Ju SW, Lin CL, Hsu WH, Lin CC, Ting IW, et al. Air pollutants and subsequent risk of chronic kidney disease and end-stage renal disease: A population-based cohort study. Environ Pollut. 2020;261:114154.

40. Ran J, Sun S, Han L, Zhao S, Chen D, Guo F, et al. Fine particulate matter and cause-specific mortality in the Hong Kong elder patients with chronic kidney disease. Chemosphere. 2020;247:125913.

41. Wang W, Wu C, Mu Z, Gu Y, Zheng Y, Ren L, et al. Effect of ambient air pollution exposure on renal dysfunction among hospitalized patients in Shanghai, China. Public Health. 2020;181:196-201.

42. Yang YR, Chen YM, Chen SY, Chan CC. Associations between Long-Term Particulate Matter Exposure and Adult Renal Function in the Taipei Metropolis. Environ Health Perspect. 2017;125(4):602-7.

43. Jung J, Park JY, Kim YC, Lee H, Kim E, Kim YS, et al. Effects of air pollution on mortality of patients with chronic kidney disease: A large observational cohort study. Sci Total Environment. 2021;786:147471.

44. Ghazi L, Drawz PE, Berman JD. The association between fine particulate matter (PM2. 5) and chronic kidney disease using electronic health record data in urban Minnesota. J Exposure Sci Environ Epidemiol. 2021:1-7.

45. Liang Z, Wang W, Wang Y, Ma L, Liang C, Li P, et al. Urbanization, ambient air pollution, and prevalence of chronic kidney disease: A nationwide cross-sectional study. Environ Int. 2021;156:106752.

46. Bo Y, Brook JR, Lin C, Chang L-y, Guo C, Zeng Y, et al. Reduced Ambient PM2. 5 Was Associated with a Decreased Risk of Chronic Kidney Disease: A Longitudinal Cohort Study. Environ Sci Technol. 2021:55(10):6876-83.

47. Zeng Y, Lin C, Guo C, Bo Y, Chang L-y, Lau AK, et al. Combined effects of chronic PM2. 5 exposure and habitual exercise on renal function and chronic kidney disease: A longitudinal cohort study. Int J Hyg Environ Health. 2021;236:113791.

48. Li G, Huang J, Wang J, Zhao M, Liu Y, Guo X, et al. Long-term exposure to ambient PM2. 5 and increased risk of CKD prevalence in China. J Am Soc Nephrol. 2021;32(2):448-58.

49. Kuźma Ł, Małyszko J, Bachórzewska-Gajewska H, Kralisz P, Dobrzycki S. Exposure to air pollution and renal function. Sci Rep. 2021;11(1):1-9.

50. Wu C-D, Chern Y-R, Pan W-C, Lung S-CC, Yao T-C, Tsai H-J, et al. Effects of surrounding environment on incidence of end stage renal disease. Sci Total Environment. 2020:137915

51. Bowe B, Xie Y, Li T, Yan Y, Xian H, Al-Aly Z. Particulate matter air pollution and the risk of incident CKD and progression to ESRD. J Am Soc Nephrol. 2018;29(1):218-30.

52. Ran J, Yang A, Sun S, Han L, Li J, Guo F, et al. Long-Term Exposure to Ambient Fine Particulate Matter and Mortality from Renal Failure: A Retrospective Cohort Study in Hong Kong. Am J Epidemiol. 2020.

53. Lin Y-T, Lo Y-C, Chiang H-Y, Jung C-R, Wang C-M, Chan T-C, et al. Particulate Air Pollution and Progression to Kidney Failure With Replacement Therapy: An Advanced CKD Registry-Based Cohort Study in Taiwan. Am J Kidney Dis; 2020.

54. Bi J, Barry V, Weil EJ, Chang HH, Ebelt S. Short-term exposure to fine particulate air pollution and emergency department visits for kidney diseases in the Atlanta metropolitan area. Environ Epidemiol. 2021;5(4).

55. Feng Y, Jones MR, Chu NM, Segev DL, McAdams-DeMarco M. Ambient air pollution and mortality among older patients initiating maintenance dialysis. Am J Nephrol. 2021;52(3):217-27.

56. Pierotti L, Schofield SJ, Collett D, Fecht D, De Hoogh K, Hansell AL, et al. Traffic-related air pollution and solid organ transplant failure in Great Britain: A retrospective cohort study. J Transport Health. 2018;10:124-31.
57. Chang S-H, Merzkani M, Murad H, Wang M, Bowe B, Lentine KL, et al. Association of ambient fine particulate matter air pollution with kidney transplant outcomes. JAMA network Open. 2021;4(10):e2128190-e.

58. Dehom S, Knutsen S, Shavlik D, Bahjri K, Ali H, Pompe L, et al. Long-Term Exposure to Fine Particulate Matter (PM2. 5) and Cardiovascular Disease Mortality among Renal Transplant Recipients. OBM Transplantation. 2019;3(4):1-.

59. Feng Y, Jones MR, Ahn JB, Garonzik-Wang JM, Segev DL, McAdamsDeMarco M. Ambient air pollution and posttransplant outcomes among kidney transplant recipients. Am J Transplant. 2021.

60. WHO's global air-quality guidelines. Lancet. 2006;368(9544):1302.

61. Levey AS, Coresh J, Tighiouart H, Greene T, Inker LA. Measured and estimated glomerular filtration rate: current status and future directions. Nature Reviews Nephrol. 2019:1-14.

62. Levey AS, Stevens LA, Schmid CH, Zhang Y, Castro AF III, Feldman HI, et al. A new equation to estimate glomerular filtration rate. Ann Intern Med. 2009; 150(9):604-12.

63. Levey AS, Bosch JP, Lewis JB, Greene T, Rogers N, Roth D. A more accurate method to estimate glomerular filtration rate from serum creatinine: a new prediction equation. Ann Intern Med. 1999;130(6):461-70.

64. Cheung KL, Lafayette RA. Renal physiology of pregnancy. Adv Chronic Kidney Dis. 2013;20(3):209-14.

65. Masson I, Flamant M, Maillard N, Rule AD, Vrtovsnik F, Peraldi M-N, et al. MDRD versus CKD-EPI equation to estimate glomerular filtration rate in kidney transplant recipients. Transplantation. 2013;95(10):1211-7.

66. Chen Y-W, Chen H-H, Wang T-E, Chang C-W, Chang C-W, Wu C-J. Difference between CKD-EPI and MDRD equations in calculating glomerular filtration rate in patients with cirrhosis. World J Gastroenterol. 2011;17(40):4532

67. Eknoyan G, Lameire N, Eckardt K, Kasiske B, Wheeler D, Levin A, et al. KDIGO 2012 clinical practice guideline for the evaluation and management of chronic kidney disease. Kidney Int. 2013;3(1):5-14.

68. Bikbov B, Perico N, Abbate M, Remuzzi G. The Glomerulus: Mechanisms and Patterns of Injury. Comprehensive Toxicology: Third Edition2017. p. 189-206.

69. Pennemans V, De Winter LM, Munters E, Nawrot TS, Van Kerkhove E, Rigo J-M, et al. The association between urinary kidney injury molecule 1 and urinary cadmium in elderly during long-term, low-dose cadmium exposure: a pilot study. Environ Health. 2011;10(1):1-7.

70. Genovese F, Manresa AA, Leeming DJ, Karsdal MA, Boor P. The extracellular matrix in the kidney: a source of novel non-invasive biomarkers of kidney fibrosis? Fibrogenesis Tissue Repair. 2014;7(1):4.

71. Lamb EJ, Path F, Price CP. 21 Kidney Function Tests-Creatinine, Urea, and Uric Acid. Tietz Fundamentals of Clinical Chemistry and Molecular Diagnostics-E-Book. 2014:364.

72. Shlipak MG, Matsushita K, Ärnlöv J, Inker LA, Katz R, Polkinghorne KR, et al, Cystatin $C$ versus creatinine in determining risk based on kidney function. N Engl J Med. 2013;369(10):932-43.

73. Argyropoulos CP, Chen SS, Ng Y-H, Roumelioti M-E, Shaffi K, Singh PP, et al. Rediscovering beta-2 microglobulin as a biomarker across the spectrum of kidney diseases. Front Med. 2017:4:73.

74. Penders J, Delanghe JR. Alpha 1-microglobulin: clinical laboratory aspects and applications. Clin Chimica Acta. 2004;346(2):107-18.

75. Norden AG, Lapsley M, Unwin RJ. Urine retinol-binding protein 4: a functional biomarker of the proximal renal tubule. Adv Clin Chem. 2014;63:85-122.

76. Ronco P, Debiec H. Pathophysiological advances in membranous nephropathy: time for a shift in patient's care. Lancet. 2015;385(9981):1983-92.

77. Bernatsky S, Smargiassi A, Johnson M, Kaplan GG, Barnabe C, Svenson $\mathrm{L}$, et al. Fine particulate air pollution, nitrogen dioxide, and systemic autoimmune rheumatic disease in Calgary. Alberta Environ Res. 2015;140:474-8.

78. Faustini A, Renzi M, Kirchmayer U, Balducci M, Davoli M, Forastiere F. Short-term exposure to air pollution might exacerbate autoimmune diseases. Environ Epidemiol. 2018;2(3):e025.

79. Darrow LA, Klein M, Flanders WD, Mulholland JA, Tolbert PE, Strickland MJ. Air pollution and acute respiratory infections among children 0-4 years of age: an 18-year time-series study. Am J Epidemiol. 2014;180(10):968-77. 
80. Zhao J, Li M, Wang Z, Chen J, Zhao J, Xu Y, et al. Role of PM 2.5 in the development and progression of COPD and its mechanisms. Respir Res. 2019;20(1):120

81. Long M-h, Zhang C, Xu D-q, Fu W-I, Gan X-d, Li F, et al. PM2. 5 aggravates diabetes via the systemically activated IL-6-mediated STAT3/SOCS3 pathway in rats' liver. Environ Pollut. 2020;256:113342.

82. HeckTG, Fiorin PBG, Frizzo MN, Ludwig MS. Fine Particulate Matter (PM2. 5) Air Pollution and Type 2 Diabetes Mellitus (T2DM): When Experimental Data Explains Epidemiological Facts. Diabetes Complications. 2018:71.

83. Pecoits-Filho R, Abensur H, Betônico CC, Machado AD, Parente EB, Queiroz M, et al. Interactions between kidney disease and diabetes: dangerous liaisons. Diabetol Metab Syndr. 2016;8(1):50.

84. Xu X, Liu C, Xu Z, Tzan K, Zhong M, Wang A, et al. Long-term exposure to ambient fine particulate pollution induces insulin resistance and mitochondrial alteration in adipose tissue. Toxicol Sci. 2011;124(1):88-98.

85. Zelnick LR, Weiss NS, Kestenbaum BR, Robinson-Cohen C, Heagerty PJ, Tuttle K, et al. Diabetes and CKD in the United States population, 2009-2014. Clin J Am Soc Nephrol. 2017;12(12):1984-90.

86. Go AS, Chertow GM, Fan D, McCulloch CE, Hsu C-y. Chronic kidney disease and the risks of death, cardiovascular events, and hospitalization. N Engl J Med. 2004;351(13):1296-305.

87. Kundu S, Stone EA. Composition and sources of fine particulate matter across urban and rural sites in the Midwestern United States. Environ Sci Proc Impacts. 2014;16(6):1360-70.

88. Zhang Z, Chang L-y, Lau AK, Chan T-C, Chieh Chuang Y, Chan J, et al. Satellite-based estimates of long-term exposure to fine particulate matter are associated with C-reactive protein in 30034 Taiwanese adults. Int J Epidemiol. 2017;46(4):1126-36.

89. Pugh D, Gallacher PJ, Dhaun N. Management of hypertension in chronic kidney disease. Drugs. 2019;79(4):365-79.

90. Hodgkins KS, Schnaper HW. Tubulointerstitial injury and the progression of chronic kidney disease. Pediatric Nephrol. 2012;27(6):901-9.

91. Pandey P, Patel D, Khan A, Barman S, Murthy R, Kisku G. Temporal distribution of fine particulates (PM2. 5, PM10), potentially toxic metals, PAHs and Metal-bound carcinogenic risk in the population of Lucknow City, India. J Environ Sci Health Part A. 2013;48(7):730-45.

\section{Publisher's Note}

Springer Nature remains neutral with regard to jurisdictional claims in published maps and institutional affiliations. 